\title{
Forest floor temperature and greenness link significantly to canopy attributes in South Africa's fragmented coastal forests
}

\author{
Marion Pfeifer ${ }^{\text {Corresp., }}{ }^{1}$, Michael JW Boyle ${ }^{2}$, Stuart Dunning ${ }^{3}$, Pieter I Olivier ${ }^{4}$ \\ 1 Modelling, Evidence \& Policy Group, SNES, Newcastle University, Newcastle Upon Tyne, United Kingdom \\ 2 Forest Ecology and Conservation Group, Silwood Park Campus, Imperial College London, Ascot, Berkshire, United Kingdom \\ 3 School of Geography, Politics and Sociology, Newcastle University, Newcastle Upon Tyne, United Kingdom \\ 4 M.A.P. Scientific Services, Pretoria, South Africa \\ Corresponding Author: Marion Pfeifer \\ Email address: marion.pfeifer@ncl.ac.uk
}

Tropical landscapes are changing rapidly due to changes in land use and land management. Being able to predict and monitor land use change impacts on species for conservation or food security concerns requires the use of habitat quality metrics, that are consistent, can be mapped using above-ground sensor data and are relevant for species performance. Here, we focus on ground surface temperature (Thermal ${ }_{\text {ground }}$ ) and ground vegetation greenness $\left(N D V I_{\text {down }}\right)$ as potentially suitable metrics of habitat quality. Both have been linked to species demography and community structure in the literature. We test whether they can be measured consistently from the ground and whether they can be up-scaled indirectly using canopy structure maps (Leaf Area Index, LAI, and Fractional vegetation cover, FCover) developed from Landsat remote sensing data. We measured Thermal $I_{\text {ground }}$ and $N D V I_{\text {down }}$ across habitats differing in tree cover (natural grassland to forest edges to forests and tree plantations) in the human-modified coastal forested landscapes of Kwa-Zulua Natal, South Africa. We show that both metrics decline significantly with increasing canopy closure and leaf area, implying a potential pathway for upscaling both metrics using canopy structure maps derived using earth observation. Specifically, our findings suggest that opening forest canopies by $20 \%$ or decreasing forest canopy LAI by one unit would result in increases of Thermal ground by $1.2^{\circ} \mathrm{C}$ across the range of observations studied. $N D V I_{\text {down }}$ appears to decline by 0.1 in response to an increase in canopy $L A l$ by 1 unit and declines nonlinearly with canopy closure. Accounting for microscale variation in temperature and resources is seen as essential to improve biodiversity impact predictions. Our study suggests that mapping ground surface temperature and ground vegetation greenness utilising remotely sensed canopy cover maps could provide a useful tool for mapping habitat quality metrics that matter to species. However, this approach will be constrained by the predictive capacity of models used to map fieldderived forest canopy attributes. Furthermore, sampling efforts are needed to capture 
spatial and temporal variation in Thermal ${ }_{\text {ground }}$ within and across days and seasons to validate the transferability of our findings. Finally, whilst our approach shows that surface temperature and ground vegetation greenness might be suitable habitat quality metric used in biodiversity monitoring, the next step requires that we map demographic traits of species of different threat status onto maps of these metrics in landscapes differing in disturbance and management histories. The derived understanding could then be exploited for targeted landscape restoration that benefits biodiversity conservation at the landscape scale. 
5 a Modelling, Evidence \& Policy Group, SNES, Newcastle University, Newcastle Upon Tyne, United $6 \quad$ Kingdom. Email: marion.pfeifer@newcastle.ac.uk.

7 b Forest Ecology and Conservation Group, Imperial College London, Silwood Park Campus, Ascot, 8 Berkshire, United Kingdom. Email: michael.boyle11@imperial.ac.uk

9 c School of Geography, Politics and Sociology, Newcastle University, Newcastle Upon Tyne, United

10 Kingdom. Email: stuart.dunning@ncl.ac.uk

11 d M.A.P. Scientific Services, Pretoria, South Africa. Email: pieter@mapss.co.za

* Corresponding author: marion.pfeifer@newcastle.ac.uk,+44 7732327961

\section{Abstract}

16 Tropical landscapes are changing rapidly due to changes in land use and land management. Being able to

17 predict and monitor land use change impacts on species for conservation or food security concerns requires

18 the use of habitat quality metrics that are consistent, can be mapped using above-ground sensor data and

19 are relevant for species performance. Here, we focus on ground surface temperature (Thermal ground $_{\text {) }}$ and

20 ground vegetation greenness $\left(N D V I_{\text {down }}\right)$ as potentially suitable metrics of habitat quality. Both have been

21 linked to species demography and community structure in the literature. We test whether they can be

22 measured consistently from the ground and whether they can be up-scaled indirectly using canopy structure

23 maps (Leaf Area Index, LAI, and Fractional vegetation cover, FCover) developed from Landsat remote

24 sensing data. We measured Thermal ${ }_{\text {ground }}$ and $N D V I_{\text {down }}$ across habitats differing in tree cover (natural

25 grassland to forest edges to forests and tree plantations) in the human-modified coastal forested landscapes

26 of Kwa-Zulua Natal, South Africa. We show that both metrics decline significantly with increasing canopy 
27 closure and leaf area, implying a potential pathway for upscaling both metrics using canopy structure maps

28 derived using earth observation. Specifically, our findings suggest that opening forest canopies by $20 \%$ or

29 decreasing forest canopy LAI by one unit would result in increases of Thermal $g_{\text {ground }}$ by $1.2^{\circ} \mathrm{C}$ across the

30 range of observations studied. $N D V I_{\text {down }}$ appears to decline by 0.1 in response to an increase in canopy $L A I$

31 by 1 unit and declines nonlinearly with canopy closure. Accounting for micro-scale variation in temperature

32 and resources is seen as essential to improve biodiversity impact predictions. Our study suggests that

33 mapping ground surface temperature and ground vegetation greenness utilising remotely sensed canopy

34 cover maps could provide a useful tool for mapping habitat quality metrics that matter to species. However,

35 this approach will be constrained by the predictive capacity of models used to map field-derived forest

36 canopy attributes. Furthermore, sampling efforts are needed to capture spatial and temporal variation in

37 Thermal $l_{\text {ground }}$ within and across days and seasons to validate the transferability of our findings. Finally,

38 whilst our approach shows that surface temperature and ground vegetation greenness might be suitable

39 habitat quality metric used in biodiversity monitoring, the next step requires that we map demographic traits

40 of species of different threat status onto maps of these metrics in landscapes differing in disturbance and

41 management histories. The derived understanding could then be exploited for targeted landscape restoration

42 that benefits biodiversity conservation at the landscape scale.

\section{Highlights}

- Ground surface temperatures and vegetation greenness vary between habitat types.

- Both decline with increasing canopy closure (FCover) and leaf area (LAI).

- For FCover increasing by $20 \%$, temperature declined by $1.2^{\circ} \mathrm{C}$ and greenness declined non-linearly.

48 - For LAI increasing by 1 unit, temperature declined by $1^{\circ} \mathrm{C}$ and greenness by 0.1 .

- Upscaling temperature and greenness is constrained by canopy attributes' maps. 


\section{Introduction}

56 In increasing parts of the tropics, landscapes are experiencing anthropogenic loss and degradation of natural

57 habitats, including primary forests, woodlands, and grasslands. The outcomes are landscape mosaics that 58 comprise patches of natural habitat and regrowth, tree plantations and croplands of differing extents and 59 management intensities. The subsequent erosion of biodiversity in these landscapes (Gibson et al., 2011) is

60 an important global challenge for biodiversity conservation as well as climate change mitigation and food

61 security (Godfray et al., 2010). Natural habitats deliver carbon storage, hydrology and microclimate

62 regulation services and supply resources used in construction, energy generation and trade. They typically harbour more species (Gibson et al., 2011) and more threatened species (Pfeifer et al., 2017) compared to plantations or croplands.

However, the fate of individual species following land use and management changes are difficult to predict for at least three key reasons. First, we lack detailed knowledge on habitat and resource needs at

67 landscape scales for many species, in particular in the tropics. Second, many models ignore that species perceive landscapes as continuous gradients in habitat quality and resource availability rather than as discrete categories of usable and unusable habitat (but see Pfeifer et al., 2017). Third, we lack common indicators characterising habitat quality, which so far has been measured through various structural 71 attributes characterising habitats or impacts on species' demographic traits (Chaplin-Kramer et al., 2015).

72 Calls for standardised landscape metrics describing continuous variations in habitat quality to improve our 73 ability to predict species responses to land use changes at the landscape scale are increasing (Mortelliti,

74 Amori \& Boitani, 2010; Pfeifer et al., 2017). Remote sensing has been advocated in the biodiversity

75 literature as an ideal tool to obtain such metrics (Pettorelli et al., 2016), providing land surface data that are 76 consistent, borderless, global and can be repeated across time. However, existing remote sensing derived 
77 metrics tend to focus on biomass or canopy vegetation productivity, which show inconclusive relationships 78 with habitat attributes that matter to species.

79 In contrast, temperature variation within forest stands and vegetation growth on the forest floor have

80 been linked to species performance and community structure. Temperature is a key driver for the growth,

81 survival, and abundance of species, and in particular insects (Bale et al., 2002). Temperature can control

82 species interactions (Rae et al., 2006; Hemmings \& Andrew, 2017), community composition and diversity

83 with reports of shifts in the abundance of insect species tracking fluctuations in ground surface temperature

84 (Thermal ground $_{1}$ (Retana \& Cerdá, 2000). Climate effects on physiology and survival are also among the key

85 hypothesised drivers of altitudinal migration among tropical bird (Barçante, M. Vale \& Maria, 2017) and

86 bat (Mcguire \& Boyle, 2013) communities. The productivity of the ground vegetation, which in forested

87 stands constitutes the herbaceous layer, is also likely to play an important ecological role for species

88 (Gilliam, 2007). Ground vegetation growth, here measured as the normalised difference vegetation index

89 of the ground vegetation $\left(N D V I_{\text {down }}\right)$, mediates nutrient fluxes, produces short-lived aboveground biomass

90 and provides resources to ground-dwelling organisms (Bromham et al., 1999; Stork \& Grimbacher, 2006).

91 Forest canopy structure can be up-scaled from plots and mapped using remote sensing data (Hadi et

92 al., 2017; Pfeifer et al., 2012, 2016). For example, forest leaf area index, $L A I$, and fractional vegetation

93 cover, FCover, measured in a forest landscape in Borneo showed mathematical relationships with satellite-

94 derived spectral and texture information, which allowed mapping $L A I$ and FCover for each pixel in the

95 landscape (Pfeifer et al., 2016). Forest canopies are also mechanistically linked to both temperature and

96 ground vegetation productivity through their effects on radiation fluxes within forest stands (Deardorff,

97 1978). Forest canopy structure modulates air temperature within forests (Hardwick et al., 2015; Von Arx et

98 al., 2012) and growth of the herbaceous layer (Royo et al., 2010; Shirima et al., 2015). Canopy cover

99 insulates against temperature extremes and macroclimatic changes (Suggitt et al., 2011), while changes in

100 canopy cover are expected to underlie temperature changes along gradients of forest degradation (Blonder

101 et al., 2018), along forest edges (Didham \& Lawton, 1999; Ewers \& Banks-Leite, 2013), and with forest

102 conversion to other land uses (Hardwick et al., 2015; Meijide et al., 2018). Using canopy structure maps 
103 with statistical models describing relationships between canopy structure and $N D V I_{\text {down }}$ and Thermal $_{\text {ground }}$

104 should hence provide an indirect way to upscale and map $N D V I_{\text {down }}$ and Thermal ${ }_{\text {ground }}$ at landscape scale.

105 A key challenge for upscaling $N D V I_{\text {down }}$ and Thermal ${ }_{\text {ground }}$ using canopy structure maps is to test

106 whether general rules exist linking vegetation canopy structure to changes in Thermal $l_{\text {ground }}$ and $N D V I_{\text {down }}$.

107 Here, we focus on Thermal $_{\text {ground }}$ and $N D V I_{\text {down }}$ as indicators of habitat quality in coastal human-modified

108 landscapes of Kwa-Zulu Natal, South Africa. We test for habitat quality variation along gradients of tree

109 cover from 0 (grassland) to $>50 \%$ (natural coastal forests and Eucalyptus timber plantations) and measure

110 across edges separating forests from other habitats. We test the following three main hypotheses:

111 Thermal $l_{\text {ground }}$ increases with $N D V I_{\text {down }}$ based on the mechanistic understanding that vegetation acts as heat

112 and water reservoir (Matthews, 2005). $N D V I_{\text {down }}$ declines with increasing canopy closure, leaf area and

113 canopy greenness $\left(N D V I_{u p}\right)$ due to decreases in light availability on the forest floor hampering ground

114 vegetation growth. Thermal ${ }_{\text {ground }}$ declines with increasing FCover and LAI, as both not only act to filter out

115 sun light but also prevent vertical mixing of air below the vegetation canopy (Hardwick et al., 2015). If our

116 expectations on relationships between vegetation canopy structure and Thermal ${ }_{\text {ground }}$ as well as $N D V I_{\text {down }}$

117 hold, this would provide a suitable way to develop upscaling algorithms for Thermal $l_{\text {ground }}$ and $N D V I_{\text {down }}$ in

118 tropical landscapes based on mapping canopy structure.

119

120 2. Material and Methods

121

$122 \quad 2.1$ Study Area

123 Fieldwork was implemented in the KwaZulu-Natal province of South Africa between April $7^{\text {th }}$ and April

$12422^{\text {nd }} 2018$ (Fig. 1). We concentrated our field campaigns on the coastal landscapes, which comprise

125 fragments of coastal forests remaining after long-term historical and recent forest loss (Olivier, van Aarde

126 \& Lombard, 2013), large tree plantations, small patches of natural grasslands and croplands. The forests

127 represent the southernmost end of East African Tropical Coastal Forest which extends from tropical central

128 Africa along the east African coast (Burgess, Clarke \& Rodgers, 1998). They occur within the Maputaland- 
129 Pondoland-Albany biodiversity hotspot and the Maputaland Centre of Plant Endemism (Wyk \& Smith,

130 2001), which support high levels of floristic endemism as well as a number of narrowly endemic species,

131 including relict species. The climate of the study region is humid and sub-tropical with annual rainfall

132 averaging $977 \pm 149 \mathrm{~mm}_{\text {year }}^{-1}$ and annual air temperature averaging $21.6 \pm 1.0^{\circ} \mathrm{Celsius}$ (Worldclim data

133 published by Fick \& Hijmans, 2017).

134

1352.2 Data collection and processing

136 We sampled 35 plots for habitat quality attributes, i.e. measuring Thermal ${ }_{\text {ground }}$ using an Optris PI450

137 Thermal Imaging Camera (382 x 288 Pixels, $29^{\circ}$ lens angle, $0.04 \mathrm{~K}$ thermal resolution, 7.5 - $13 \mu \mathrm{m}$ spectral

138 range) and $N D V I_{\text {down }}$ as normalised difference vegetation index (NDVI) using a MAPIR camera (MAPIR,

139 Peau Productions Inc., San Diego CA, US) with filters for the Red (660 nm) and Near-Infrared (850 nm)

140 parts of the electromagnetic spectrum (16 MP sensor: 4608 x 3456 Pixels, $82^{\circ}$ HFOV (23mm) f/2.8

141 Aperture. We measured $L A I$ and FCover using hemispherical photography using a Canon 5D Mark II with

142 a Sigma 2.8 fisheye lens and $N D V I_{u p}$ using the MAPIR camera facing upwards.

143 The thermal camera used in this study has an internal sensor that delivers ambient temperature values

144 by default and takes them into account during measurements. The camera also implements offset 145 calibrations accounting for thermal drift in the thermal detector. This is implemented by a motor driven 146 motion of a blackened metal piece (so called flag) in the front of the image sensor, so each image element

147 is referenced with the same temperature. Weather did not change considerably over the field period (sunny 148 with occasional clouds). We aimed to minimise the impact of time of day as confounding factor by acquiring 149 most data between 10 am and $2 \mathrm{pm}$. This corresponds to peak day time temperatures and solar gain, as 150 indicated by temperature recordings from nearby weather stations provided by National Climate Centre, 151 South African Weather Service (Supporting Information, Table S1). We also measured air temperature at

$1521 \mathrm{~m}$ height in the plots to test for its potential effects on Thermal ${ }_{\text {ground }}$ measurements (Senior et al., 2018).

153 Whilst appropriate for the purpose of this study, our data can only be understood as temporal snapshots of 154 ground surface temperature variations. 
156 2.2.1 Sampling Design

157 Approximate locations of transects were chosen prior to fieldwork based on our knowledge of the landscape

158 and ease of accessibility. The final transect placement within the landscape was implemented using

159 stratified random sampling. Plots were set up in five main habitat types (i.e. natural grassland, open

160 bushland, natural forests, edges of natural forests and timber plantations comprising Eucalytpus species)

161 located along linear transects (Fig. 2). We sampled a total of 11 transects (Supporting Information, Table

$162 \mathrm{~S} 1)$ : six transects across natural forest - edge - natural grassland habitats (T01, T02, T07-T10), four

163 transects stretching across natural forest - edge - Eucalyptus plantation habitats (T03-T06) and one transect

164 stretching across natural forest - edge - natural grassland - bush habitats (T11). Forests comprised three

165 different forest types: coastal lowland forest, scarp forest and peatland forest. Each transect comprised three

166 plots (one per habitat type) except for T11, which comprised five plots (two bushland plots).

167 We increased sampling effort for measurements of canopy structure, which were used to develop

168 upscaling algorithms for predicting and mapping canopy structure in the landscape using remote sensing

169 data: we sampled an additional 17 forest (including woodlands) and seven plantation (one: needle-leaved

170 trees, six: fruit trees) plots during this field study. We additionally used hemispherical images acquired

171 from 52 forests between 22/06/2015 and 05/07/2015 (Rolo et al., 2017) and from 11 needle-leaved tree

172 plantations between 11/08/2015 and 13/08/2015 across the coastal landscape (Fig. 1).

173

174 2.2.2 Collection of habitat quality data

175 We acquired fisheye images in habitat quality plots of $20 \mathrm{~m}$ x $20 \mathrm{~m}$ dimensions following standard protocols

176 (Pfeifer, 2015). In brief, at each plot, we took on average 12 high-resolution images through a digital camera

177 and equipped with a hemispherical (fish-eye) lens with sampling points distributed within the plot (Fig. 2a)

178 following the VALERI design (VAlidation of Land European Remote Sensing Instruments) and hence

179 standard protocols developed for the Global LAI Project (Pfeifer, 2015). The camera was held at $1 \mathrm{~m}$ above 
180 ground, looking vertically upward from beneath the canopy. The levelled hemispherical photographs were

181 acquired normal to a local horizontal datum, orienting the optical axis of the lens to local zenith.

182 We acquired NDVI images of the ground vegetation greenness (pointing the NDVI camera downward,

$183 N D V I_{\text {down }}$ ) and of canopy greenness (pointing the NDVI camera upwards, $N D V I_{u p}$ ). We also acquired an

184 image of the MAPIR ground target (i.e. targets of known reflectance values) at the start of each survey and

185 we repeated this throughout the day if sky conditions changed. We acquired $N D V I_{\text {down }}$ and $N D V I_{u p}$ images

186 at five sample points for each plot. Ground images were acquired using a 50 x $50 \mathrm{~cm}$ square made of metal

187 rulers to delineate boundaries around each point (Fig. 2a). At each sampling point, we measured

188 Thermal $_{\text {ground }}$ as radiometric corrected values (saved as snapshots in $*^{*} \operatorname{csv}$ matrix format) pointing the

189 thermal camera downwards, again using the $50 \times 50 \mathrm{~cm}$ grids made from metal rulers to indicate boundaries

190 around each sampling point. Thermal ${ }_{\text {ground }}$ data acquisition failed for the grassland plot at T02, which was

191 excluded in relevant analyses.

192

193 2.2.3 Processing of habitat quality data

194 Leaf area index (sensu Plant Area Index, $L A I$, corrected for foliage clumping) was estimated from the

195 fisheye images at plot level. Fractional vegetation cover (sensu canopy closure, FCover, in \%) was

196 estimated for each image and hence sampling point. Fisheye images were first processed using 'in-house'

197 algorithms (available for download from the Global LAI Project websites:

198 https://globallai.wordpress.com/publications/) and the freeware CAN-EYE v 6.3.8 (Weiss \& Baret, 2010),

199 following standard steps (Pfeifer et al., 2012). In brief, the 'in-house' algorithms extracted the blue band

200 from each fisheye image as the blue band achieves maximum contrast between leaf and sky. This is because

201 absorption of leafy materials is maximal and sky scattering tends to be highest in that band (Jonckheere,

202 Muys \& Coppin, 2005a). The algorithm then applied the global Ridler \& Calvard method (Ridler \&

203 Calvard, 1978) to the blue band extracted from each image for identifying the optimal brightness threshold

204 that distinguishes vegetation from sky (Jonckheere, Muys \& Coppin, 2005b). The algorithm then used the

205 threshold derived for each image to create binary images of vegetation and sky from the blue band images, 
206 which were subsequently processed in the canopy analysis software CAN-EYE V6.3.8 (Weiss \& Baret, 207 2010) limiting the field of view of the lens to values between 0 and $60^{\circ}$ to avoid mixed pixels and thus 208 misclassifications. Our approach thus estimates LAI as plant area index (PAI), which includes materials 209 such as stems, trunks, branches, and twigs, and plant reproductive parts (Breda, 2003). This approach is

210 used in other indirect measurements of LAI and acknowledges that masking some parts of the plants to

211 keep only the visible leaves is not correct and could lead to large underestimation of the actual LAI value

212 as some leaves are present behind the stems, branches or trunk (Hardwick et al., 2015).

213 Each NDVI image was calibrated using the MAPIR Plugin (https://github.com/mapircamera/QGIS)

214 within the spatial analysis software Quantum GIS v2.14.3. The plugin first loads the ground target image

215 to find the calibration values. It then calibrates all survey images using those values. We subsequently

216 processed calibrated NDVI images and thermal images to summary statistics using R statistical software

217 (R Core Team, 2018) following steps outlined in table 1. For some samples and plots, calibration produced

218 non-sensible results for $N D V I_{\text {down }}$ and those samples and plots were excluded from the relevant analyses

219 (the forest plots in T02 - T05 and T07 and the plantation plot in T03). The errors resulted from missing at220 plot ground target images preventing us from calibrating images accurately.

221

222 2.3 Statistical analyses of habitat quality data

223 We used the R statistical software package version 3.5.1 for all statistical analyses (R Core Team, 2018).

224 Statistics of quality data for habitats were summarised using boxplots generated on plot level data (LAI) 225 and sample points $\left(N D V I_{u p}, N D V I_{\text {down }}\right.$, FCover, Thermal $\left.{ }_{\text {ground }}\right)$ (Fig. 3). We used pairwise Wilcoxon tests 226 with Bonferroni adjustments to test for significant differences in in the summary statistics between habitat 227 types sampled. We expected higher values of $N D V I_{\text {down }}$ and Thermal $_{\text {ground }}$ corresponding with lower values 228 of FCover and LAI in open habitat types such as bushland and edges compared to forest interior and 229 Eucalyptus plantations.

230 We aggregated FCover, $N D V I_{\text {down }}, N D V I_{\text {up }}$, and Thermal ground at plot level (LAI estimates were 231 estimated at plot level only). Subsequently, grassland plots (no trees present) were assigned values of '0' 
232 for forest canopy $L A I$ and FCover and values of '-1' for $N D V I_{u p}$. We developed linear and general additive

233 models, the latter using the gam function in the mgcv package (Wood, 2017), to test for single predictor

234 relationships between $N D V I_{\text {down }}$ or Thermal ground and $N D V I_{u p}, F C o v e r$ or $L A I$. We selected the final models

235 based on explained variance (i.e. higher adjusted R-squared). If both models produced the same estimates

236 of adjusted R-squared, we subsequently discuss findings from the simpler, linear model. Specifically, we

237 tested for changes in mean, minimum and maximum of $N D V I_{d o w n}$ or Thermal ${ }_{\text {ground }}$ as a function of mean,

238 minimum and maximum of $N D V I_{u p}$ and FCover. We also tested for relationships between mean, minimum

239 and maximum of $N D V I_{\text {down }}$ and mean, minimum and maximum of Thermal ${ }_{\text {ground }}$. We tested for changes in

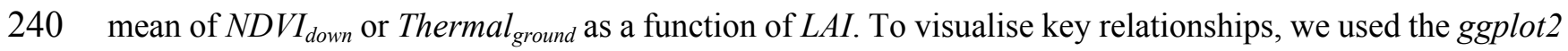

241 package (Wickham, 2016) using the smoothing function and specifying the linear or general additive model

242 dependencies. Finally, we modelled the effects of air temperature $\left(T_{\text {air }}\right)$ measured at plot level on the

243 relationship between canopy structure and Thermal ${ }_{\text {ground }}\left(\right.$ Thermal $_{\text {ground }} \sim$ FCover* $^{*} T_{\text {air }}$ ).

2452.4 Upscaling habitat quality data using Landsat imagery

246 We focused on Landsat Surface Reflectance Satellite Level-2 satellite product, i.e. satellite images that are

247 freely available online, of high geospatial accuracy, and can be downloaded as surface reflectance data for 248 comparisons over time and space (and hence are already corrected for atmospheric noise). We used two 249 Landsat scenes acquired over the study landscape on June $4^{\text {th }}$ in 2014 . We used those images to upscale 250 canopy structure data, specifically canopy leaf area index and fractional vegetation cover derived from the 251 hemispherical images. We assumed that canopy structure did not change significantly since 2014 for the 252 plots sampled, which is reasonable given the plots were located in woody ecosystems from little utilised 253 shrubs to coastal forests, the majority being located within protected areas.

254 All raster analyses were implemented using the 'raster' package' (Hijmans, 2017). We downloaded the 255 Landsat 8 surface reflectance product (LASRC), derived from the Landsat 8 Operational Land Imagery 256 data in each Landsat scene, from the USGS Earth Explorer after screening for clouds aiming to minimise 257 cloud coverage over the landscape. We processed those reflectance data by setting pixels covered with 
258 clouds or haze to NA and only using pixels for which the pixel quality attributes indicated clear conditions

259 (i.e. pixel quality attributes coded as 322, 386, 834, 898, or 1346) and excluding water bodies (i.e. pixel 260 quality attributes coded as 324, 388, 836, 900, or 1348). We used Quantum GIS spatial software (QGIS

261 Development Team, 2009) to mosaic the four scenes and cropped the extent of the raster mosaic to the 262 study area using the 'raster' package (Hijmans, 2017). Reflectance (spectral intensity) measured in the red 263 and near-infrared bands of the electromagnetic spectrum were used to compute three maps of vegetation 264 greenness (i.e. the normalised difference vegetation index, NDVI (Tucker, 1979), the modified soil-adjusted 265 vegetation index, MSAVI2 (Qi et al., 1994), and the two-band enhanced vegetation index, EVI2 (Jiang et 266 al., 2008). We used the 'glcm' (Zvoleff, 2016) package in R statistical software to obtain indices of image 267 textures for the red, near-infrared and shortwave infrared 1 bands in the Landsat imagery. We computed 268 two indices to obtain texture information for a given pixel and its neighbourhood for each of these three 269 bands: MEAN and DISSIMILARITY. This was implemented on a grey-level co-occurrence matrix with a 27090 degree shift and 64 grey-levels and a window size of $3 \times 3$ pixels for each band (Pfeifer et al., 2016).

271 We also computed mean and standard deviation maps of NDVI using the focal function in the 'raster' 272 package specifying a moving window size of 8 pixels (Hijmans, 2017).

273 To map canopy structure, we combined canopy structure data acquired in 2015 with canopy structure 274 data acquired during the fieldwork described here. We extracted reflectance, texture and vegetation 275 greenness data onto each plot. The final dataset yielded a total of 109 plots measured for canopy LAI and 276 FCover (with $\mathrm{N}=79$ forest plots, 7 woodland plots, 2 bush plots, and 21 plantation plots (including broad277 leaved and needle leaved plantations). We developed Random Forest models linking spectral, texture and 278 vegetation greenness data to canopy structure data after excluding predictor variables from the model that 279 were highly inter-correlated $(P>0.6)$. We computed the models using the 'randomForest' package (Liaw 280 \& Wiener, 2002) in R (Table 2: final predictor variables included in predictive model). We subsequently 281 used the final models to upscale plot measured canopy attributes to landscape scale excluding water bodies 282 and any other NA regions from the resulting maps. 


\section{3. Results}

285 3.1 Habitat quality variation between habitat types

286 Habitats differed significantly in habitat quality metrics measured in this study (Fig. 3). As expected,

287 Thermal $_{\text {ground }}$ decreased from grassland and bush plots to edge plots (pairwise Wilcoxon tests with

288 Bonferroni adjustment, $P<0.05)$ and then to forest plots $(P<0.001)$. Thermal ${ }_{\text {ground }}$ for plantation plots was

289 higher than for forest plots and lower than for grassland and bush plots $(P<0.01) . N D V I_{\text {down }}$ showed

290 different trends with habitat types compared to Thermal ${ }_{\text {ground }}$ and was higher in grassland, bush and

291 plantation plots compared to edge and forest plots $(P<0.05)$. FCover was higher for edge, forest and

292 woodland plots compared to plantation plots and lower in woodland versus forest plots $(P<0.05) . N D V I_{u p}$

293 was lower in plantation plots compared to forest plots $(P<0.05)$ and was marginally higher in bush

294 compared to edge plots $(P=0.052)$. Canopy $L A I$ did not differ significantly between habitats.

295

2963.2 Habitat quality attributes and their inter-relationships

297 Thermal $_{\text {ground }}$ showed significant linear dependencies on canopy attributes (Tables 2 and 3, Figures 4 and

298 5). Specifically, for each increase in FCover by $10 \%$, Thermal ${ }_{\text {ground }}$ declined by $0.6^{\circ} \mathrm{C}$ starting from $27.6^{\circ} \mathrm{C}$

299 (Fig. 4b) and for each increase in $L A I$ by 1 unit, Thermal ${ }_{\text {ground }}$ declined by $1.2^{\circ} \mathrm{C}$ decrease starting from

$30027.4^{\circ} \mathrm{C}$ (Fig. 5b). The predictive capacity of the models improved when taking into account air temperature

301 effects (Table 4). Furthermore, predicted effects indicate stronger buffering impacts of canopy closure

302 under higher levels of air temperature (Table 4).

$303 N D V I_{\text {down }}$ showed significant nonlinear declines with increasing canopy closure and linear declines

304 with increasing canopy leaf area (Tables 2 and 3, Figures 4a and 5a). Specifically, for each increase in $L A I$

305 by 1 unit, $N D V I_{\text {down }}$ declined by 0.09 starting from 0.57 (Fig. 5a). $N D V I_{\text {down }}$ showed non-linear convex

306 relationships with $N D V I_{u p}$ increasing with rising canopy greenness above an approximate threshold of

$307 N D V I_{u p}=0.0$ and increasing with declining canopy greenness (towards no trees) below that threshold (Fig. 308 4c). 
310 relationship between Thermal $_{\text {ground }}$ and $N D V I_{u p}$ disappeared when excluding grasslands (Table 2). Finally,

311 Thermal ${ }_{\text {ground }}$ and $N D V I_{\text {down }}$ correlate with each other (Fig. 4d) and data suggest that for each increase in

$312 N D V I_{\text {down }}$ by 0.1 , ground surface temperature increased by approximate $0.4^{\circ} \mathrm{C}$. This pattern held despite an

313 expected influence of measurements acquired during different times of the day (i.e. measurement bias

314 through sampling effect). The statistical model fitted to the relationship between Thermal $_{\text {ground }}$ and $N D V I_{\text {down }}$

315 underestimated Thermal ${ }_{\text {ground }}$ for five plots and overestimated it for eight plots. Plots whose Thermal ground

316 was higher than expected based on their $N D V I_{\text {down }}$ include grassland plots measured around midday (a, c,

317 d). Plots whose Thermal ground was lower than expected from their $N D V I_{\text {down }}$ include a grassland plot from

318 Ngoye (b) and a forest plot from Enseleni (e), both measured earlier in the day (10 am, slightly cooler time

319 of the day).

320

3213.3 Mapping habitat quality using upscaling algorithms

322 The predictive capacity of the habitat quality mapping using Landsat reflectance data and derived indices was limited. Random Forest models explained $35 \%$ of the variability on the $L A I$ data and $31 \%$ in the variability of FCover data (Table 5). We used the resulting LAI maps to map ground surface temperature and ground NDVI (Fig. 6) using models as detailed in the legends for Figure 5.

\section{Discussion}

328 Ground surface temperature and ground NDVI, both habitat attributes that have been linked to diversity, 329 abundance and behaviour of animal species in different studies, are positively correlated. These habitat 330 attributes are strongly linked to canopy structure attributes commonly mapped using remote sensing data.

331 Specifically, opening canopies by about $20 \%$ or reducing canopy leaf area by 1 unit, would result in an

332 increase of average temperatures on the ground by more than $1^{\circ} \mathrm{C}$. Ground vegetation greenness would 333 decline nonlinearly as a function of increasing canopy closure. 
334 These findings are not surprising based on the mechanistic understanding of radiation fluxes within 335 vegetation layers (Deardorff, 1978; Best, 1998). They are likely to have important implications for 336 microclimate within forests stands though, as tropical forests are changing rapidly with current global 337 change drivers. Forest canopies are showing stress and die-back responses to repeated droughts, the latter 338 acting in concert with other disturbance drivers to open forest canopies (Malhi et al., 2009). Disturbance 339 has been shown to decrease canopy cover in the Amazon rainforests by $13 \%$ to $60 \%$ depending on 340 disturbance intensity $($ FCover $=98 \%$ in intact forests, $85 \%$ in logged and lightly burned forests, $63 \%$ in 341 heavily logged forests and 39\% in heavily logged and burned forests) (Gerwing, 2002). Based on

342 relationships derived in this study, such canopy cover declines would translate to increases in ground 343 surface temperature of at least $3^{\circ} \mathrm{C}$ in severely disturbed forests. Our results are thus in line with findings 344 from a review on the thermal buffering capacity of forests, in which warming effects caused by land use 345 change ranged from $+1.1^{\circ} \mathrm{C}$ in degraded forests to $+2.7^{\circ} \mathrm{C}$ in plantations, $+6.2^{\circ} \mathrm{C}$ in pasture and $+7.6^{\circ} \mathrm{C}$ in 346 cropland (Senior et al., 2017). Taking into account expectations on temperature extremes during the day

347 (Blonder et al., 2018) may paint an even bleaker picture as stronger responses of temperature extremes to 348 canopy structure changes would be expected (Ewers \& Banks-Leite, 2013; Hardwick et al., 2015).

349 However, canopy cover has also been shown to recover more rapidly than forest biomass after logging 350 (Pfeifer et al., 2016). And while remotely sensed canopy structure maps from rainforests in Malaysian 351 Borneo suggest decreased canopy cover even ten years after logging and conversion to palm stands (i.e. 352 FCover was 6 to $10 \%$ lower in logged forests and $25 \%$ lower in oil palms compared to primary forests 353 (Pfeifer et al., 2016), these declines were not detectable at plot level in the field. These rapid recoveries 354 may underlie recent observations of logged forests being able to retain the thermal buffering capacities of 355 undisturbed forests (Senior et al., 2018) and further studies are warranted to investigate the spatial and 356 temporal feedbacks between forest canopy degradation, forest canopy recovery and thermal environments 357 on the forest floor over time.

358 Thermal cameras calculate the surface temperature on the basis of the emitted infrared radiation from 359 an object, which itself depends on the temperature of the environment as well as on the radiation features 
360 of the surface material of the measuring object (Kastberger \& Stachl, 2003). Adjusting emissivity values

361 for each material encompassed in the field of view of the camera might increase accuracy of our temperature

362 measurements. However, accounting for this emissivity is unlikely to significant alter the relationships we

363 found due to the camera's internal calibration. Furthermore, the surfaces we scanned are relatively similar

364 and composites of soil, leaf litter, green herbaceous vegetation and grass in varying proportions. Whilst

365 emissivity values for these materials vary with values of 0.93 (barren sandy soil), 0.96 (partial grass cover),

366 and 0.98 (short grass and grassland) over the wavelength ranges our sensor is working in, composites of

367 effective surface emissivity for soil - grass like vegetation surfaces was evaluated and estimated as mean

368 of 0.98 (Humes et al., 1994).

369 Temperature changes induced by changes in forest canopies may increase or decrease growth rate or

370 other fitness traits of species depending on the species' optimum temperature, the temperature it currently

371 experiences in its environment and the temperature it would experience after canopy changes. For example,

372 herbivores and their growth rates respond more strongly to temperature than the growth rate of plants, while

373 aboveground ectotherms show stronger thermal response of life-history traits than belowground ectotherms

374 (Berg et al., 2010). The variability in responses is likely to result in changes in the network relationships

375 between species (Berg et al., 2010) and thus species' ecological roles within forest ecosystem processes

376 (Ewers et al., 2015). Temperature effects are likely to be stronger for species in the tropics and in particular

377 tropical ectotherms in forests (Deutsch et al., 2008; Potter, Arthur Woods \& Pincebourde, 2013; Kaspari et

378 al., 2015). Tropical insects are suggested to have narrow thermal tolerances and to track air temperatures

379 close to their optimal temperature; they experience near-lethal temperatures faster than temperate insects

380 and warming is expected to reduce their population fitness by up to $20 \%$ (Deutsch et al., 2008). Ground

381 surface temperature increases are likely to act in concert with heat stress as the operational temperature of

382 ectotherms is determined by both convection (the exchange of energy between body and air) and

383 conductance (the direct transfer of energy between objects and surfaces) (Potter, Arthur Woods \&

384 Pincebourde, 2013).However, direct empirical evidence is rare and we suggest four steps following on from

385 this pilot study: 
First, to account for time of day and hence ambient temperature effects on ground surface temperature measures and to analyse interlinkages between both, ground surface temperature should be sampled together with air temperature throughout the course of the day and over several days, and if necessary seasons (e.g. dry versus wet seasons in the Afrotropics), which could be achieved using mini meteorological dataloggers and radiation sensors. This will allow us to capture variation in average temperature and temperature extremes as experienced by species in the forest understorey.

392 Second, studies could test and account for potential effects of emissivity variability. Assuming that the 393 object's temperature differs from ambient temperature this could be achieved by using a black flat object 394 of known emissivity (0.98) as calibration target with three steps: (1) adjusting the emissivity of the infrared 395 thermometer to 0.98 , (2) acquisition of the temperature of the calibration target, (3) scanning the temperature of a directly adjacent area and modify the emissivity until the measured value corresponds to the temperature of the black surface.

Third, the tropical forest floor harbours a set of insect taxa believed to be distinct from the forest canopy (Stork \& Grimbacher, 2006). Their abundance and distribution on the ground is probably linked to leaf litter (Rodgers \& Kitching, 1998), ground vegetation , availability of host plants (Novotny et al., 2002) as well as microclimate (Schulze, Linsenmair \& Fiedler, 2001). Thus, detailed species community and species behavioural studies looking at a gradient of surface temperatures along a gradient of canopy openness should be implemented for a range of taxonomic groups.

Fourth, habitat quality can have different meanings to species depending on the ecological scales they operate on and their interlinkages in trophic networks (Schulze, Linsenmair \& Fiedler, 2001). For example, ground-dwelling insects feeding on detritus may be more affected by fine scale variation in temperature (Levesque, Fortin \& Mauffette, 2002; Lessard, Dunn \& Sanders, 2009). In contrast, larger body-sized mobile bird species acquiring resources across larger spatial scales may be more affected by the availability

409 of nesting places and the distribution of prey items in the landscape (Sekercioglu et al., 2007). Network 410 analyses are rare, in particular for the tropics, but would allow us to determine whether changes in insects 
411 and ground vegetation due to microclimate changes are likely to propagate into changes in larger-body

412 sized animal groups.

413

414 5. Conclusions

415 Accounting for micro-scale variation in temperature is seen as essential to improve biodiversity impact

416 predictions using species distribution models (Suggitt et al., 2011). Thermal imaging of land surfaces can

417 be implemented using unmanned aerial vehicles (Bellvert et al., 2014) and to some extent satellite sensors

418 (Lee et al., 2015). However there are technical challenges in flying UAVs across many regions and changes

419 in temperature below vegetation canopies ('buffer effect') would be difficult to detect. Our ground-based

420 analyses show that canopy structure and below canopy ground surface temperatures show clear significant

421 relationships, which could be exploited for mapping habitat quality metrics that matter to species. However,

422 more work is needed to (1) reduce uncertainties in these relationships and (2) to improve canopy structure

423 mapping (and hence subsequent ground surface temperature mapping) using remote sensing data. Our data

424 seem to suggest that increasing sampling effort to capture spatial (along gradients of canopy cover and leaf

area) and temporal (as function of day light, climate seasonality and climate extremes) variation in ground

426

surface temperature would be beneficial to address the first point. The second point could be addressed by

using data acquired at higher spatial resolution, as we have shown for forest degradation gradients in Borneo

428

(Pfeifer et al., 2016) and by sampling canopy structure variation for a wide range of habitat types on the ground resolution. Either way, linking ground surface temperature (maps) to species demographic traits and abundance distributions in predictive biodiversity modelling (Pfeifer et al., 2017) would be the next essential step to truly determine the choice of ground surface temperatures as suitable habitat quality metric.

432 This could then be exploited to design landscapes that maximise benefits from habitat restoration and 433 management for biodiversity conservation and other ecosystem services.

\section{Acknowledgements}


436 We acknowledge the logistic support of M.A.P. Scientific Services (https://www.mapss.co.za/, Pretoria,

437 info@mapss.co.za) in the field. We thank the National Climate Centre of South African Weather Service

438 for providing weather station data at hourly resolutions acquired at weather stations near the field plots 439 during the field period.

440

\section{References}

442 Bale JS., Masters GJ., Hodkinson ID., Awmack C., Bezemer TM., Brown VK., Butterfield J., Buse A., 443 Coulson JC., Farrar J., Good JEG., Harrington R., Hartley S., Jones TH., Lindroth RL., Press MC., 444 Symrnioudis I., Watt AD., Whittaker JB.2002. Herbivory in global climate change research: direct 445 effects of rising temperature on insect herbivores. Global Change Biology 8: 1-16. DOI: 10.1046/j.1365-2486.2002.00451.x.

Barçante L., M. Vale M., Maria MA. 2017. Altitudinal migration by birds: a review of the literature and a comprehensive list of species. Journal of Field Ornithology 88: 321-335. DOI: 10.1111/jofo.12234.

Bellvert J., Zarco-Tejada PJ., Girona J., Fereres E. 2014. Mapping crop water stress index in a 'Pinotnoir' vineyard: comparing ground measurements with thermal remote sensing imagery from an unmanned aerial vehicle. Precision Agriculture 15: 361-376. DOI: 10.1007/s11119-013-9334-5.

Berg MP., Kiers ET., Driessen G., van der Heijden M., Kooi BW., Kuenen F., Liefting M., Verhoef HA., Ellers J. 2010. Adapt or disperse: understanding species persistence in a changing world. Global Change Biology 16: 587-598. DOI: 10.1111/j.1365-2486.2009.02014.x.

Best MJ. 1998. A Model to Predict Surface Temperatures. Boundary-Layer Meteorology 88:279-306. DOI: $10.1023 / \mathrm{A}: 1001151927113$.

Blonder B., Both S., Coomes D., Elias D., Jucker T., Kvasnica J., Majalap N., Malhi YS., Milodowski D., Riutta T., Svatek M. 2018. Extreme and highly heterogeneous microclimates in selectively logged tropical forests. Frontiers in Forests and Global Change. DOI: 10.3389/ffgc.2018.00005.

Bromham L., Cardillo M., Bennett AF., Elgar MA. 1999. Effects of stock grazing on the ground invertebrate fauna of woodland remnants. Austral Ecology 24: 199-207. DOI: 10.1046/j.1442- 
9993.1999.00963.x.

463 Breda, NJJ. 2003. Ground-based measurements of leaf area index: a review of methods, instruments and 464 current controversies. Journal of Experimental Botany 54: 2403-2417. DOI: 10.1093/jxb/erg263.

465 Burgess ND., Clarke GP., Rodgers WA. 1998. Coastal forests of eastern Africa: Status, endemism 466 patterns and their potential causes. Biological Journal of the Linnean Society 64: 337-367. DOI:

$467 \quad$ 10.1006/bijl.1998.0224.

468 Chaplin-Kramer R., Sharp RP., Mandle L., Sim S., Johnson J., Butnar I., Canals LM., Eichelberger BA., 469 Ramler I., Mueller C., McLachlan N., Yousefi A., King H., Kareiva PM. 2015. Spatial patterns of 470 agricultural expansion determine impacts on biodiversity and carbon storage. Proceedings of the $471 \quad$ National Academy of Sciences of the United States of America 112: 7402-7. DOI: 10.1073/pnas.1406485112.

Deardorff JW. 1978. Efficient prediction of ground surface temperature and moisture, with inclusion of a layer of vegetation. Journal of Geophysical Research 83: 1889. DOI: 10.1029/JC083iC04p01889.

Deutsch CA., Tewksbury JJ., Huey RB., Sheldon, KS., Ghalambor CK., Haak DC., Martin PR.2008. Impacts of climate warming on terrestrial ectotherms across latitude. Proceedings of the National Academy of Sciences of the United States of America 105: 6668-72. DOI: 10.1073/pnas.0709472105.

Didham RK., Lawton JH. 1999. Edge Structure Determines the Magnitude of Changes in Microclimate and Vegetation Structure in Tropical Forest Fragments1. Biotropica 31: 17-30. DOI: 10.1111/j.1744-7429.1999.tb00113.x.

482 Ewers RM., Banks-Leite C. 2013. Fragmentation Impairs the Microclimate Buffering Effect of Tropical 483 Forests. PLoS ONE 8, e58093. DOI: 10.1371/journal.pone.0058093.

484 Ewers RM., Boyle MJW., Gleave RA., Plowman NS., Benedick S., Bernard H., Bishop TR., Bakhatiar 485 EY., Chey VK., Chung AYC., Davies RG., Edwards DP., Eggleton P., Fayle TM., Hardwick SR., 486 Homathevi R., Kitching RL., Khoo MS., Luke SH., March JJ., Nilus R., Pfeifer M., Rao SV., Sharp 487 AC., Snaddon JL., Stork NE., Strubig MJ., Wearn OR., Yusah KM., Turner EC. 2015. Logging cuts 
the functional importance of invertebrates in tropical rainforest. Nature Communications 6: 6836. DOI: $10.1038 /$ ncomms 7836 .

Fick SE., Hijmans R.J. 2017. Worldclim 2: New 1-km spatial resolution climate surfaces for global land areas. International Journal of Climatology 37: 4302-4315. DOI: 10.1002/joc.5086.

492

493

Gerwing JJ. 2002. Degradation of forests through logging and fire in the eastern Brazilian Amazon. Forest Ecology and Management 157: 131-141. DOI: 10.1016/S0378-1127(00)00644-7.

Gibson L., Lee TM., Koh LP., Brook BW., Gardner TA., Barlow J., Peres CA., Bradshaw CJA., Laurance WF., Lovejoy TE., Sodhi NS. 2011. Primary forests are irreplaceable for sustaining tropical biodiversity. Nature 478: 378-81. DOI: 10.1038/nature10425.

Gilliam FS. 2007. The Ecological Significance of the Herbaceous Layer in Temperate Forest Ecosystems. BioScience 57: 845-858. DOI: 10.1641/B571007.

Godfray HCJ., Beddington JR., Crute IR., Haddad L., Lawrence D., Muir JF., Pretty J., Robinson S., Thomas SM., Toulmin C.. 2010. Food Security: The Challenge of Feeding 9 Billion People. Science 327: 812-818. DOI: $10.1126 /$ science. 1185383.

Hadi., Pfeifer M., Korhonen L., Wheeler C., Rautiainen M. 2017. Forest canopy structure and reflectance in humid tropical Borneo: A physically-based interpretation using spectral invariants. Remote Sensing of Environment 201: 314-330. DOI: 10.1016/j.rse.2017.09.018.

Hardwick SR., Toumi R., Pfeifer M., Turner EC., Nilus R., Ewers RM. 2015. The relationship between leaf area index and microclimate in tropical forest and oil palm plantation: Forest disturbance drives changes in microclimate. Agricultural and Forest Meteorology 201: 187-195. DOI: 10.1016/j.agrformet.2014.11.010.

Hemmings Z., Andrew NR. 2017. Effects of microclimate and species identity on body temperature and thermal tolerance of ants (Hymenoptera: Formicidae). Austral Entomology 56: 104-114. DOI: 10.1111/aen.12215.

Hijmans RJ. 2017. raster: Geographic Data Analysis and Modeling. R package version 2.6. https://CRAN.R-project.org/package=raster 
514 Humes KS., Kustas WP., Moran MS., Nichols WD., Weltz MA. 1994. Variability of emissivity and

515 surface temperature over a sparsely vegetated surface. Water Resources Research 30: 1299-1310.

516 DOI: $10.1029 / 93$ WR03065.

517 Jiang Z., Huete AR., Didan K., Miura T. 2008. Development of a two-band enhanced vegetation index

518 without a blue band. Remote Sensing of Environment 112: 3833-3845. DOI:

$519 \quad 10.1016 /$ j.rse.2008.06.006.

520 Jonckheere IG., Muys B., Coppin PR. 2005a. Derivative analysis for in situ high dynamic range

521 hemispherical photography and its application in forest stands. Geoscience and Remote Sensing

522 Letters, IEEE 2: 296-300. DOI: 10.1109/LGRS.2005.846904.

523 Jonckheere I., Muys B., Coppin P. 2005b. Allometry and evaluation of in situ optical LAI determination

524 in Scots pine: a case study in Belgium. Tree Physiology 25: 723-732. DOI:

$525 \quad 10.1093 /$ treephys/25.6.723.

526 Kaspari M., Clay NA., Lucas J., Yanoviak SP., Kay A. 2015. Thermal adaptation generates a diversity of

527 thermal limits in a rainforest ant community. Global Change Biology 21: 1092-1102. DOI:

$528 \quad 10.1111 / \mathrm{gcb} .12750$.

529 Kastberger G., Stachl R. 2003. Infrared imaging technology and biological applications. Behavior

$530 \quad$ Research Methods, Instruments, \& Computers 35: 429-435.

531 Lee CM., Cable ML., Hook SJ., Green RO., Ustin SL., Mandl DJ., Middleton EM. 2015. An introduction 532 to the NASA Hyperspectral InfraRed Imager (HyspIRI) mission and preparatory activities. Remote 533 Sensing of Environment 167: 6-19. DOI: 10.1016/J.RSE.2015.06.012.

534 Lessard J-P., Dunn RR., Sanders NJ. 2009. Temperature-mediated coexistence in temperate forest ant 535 communities. Insectes Sociaux 56: 149-156. DOI: 10.1007/s00040-009-0006-4.

536 Levesque KR., Fortin M., Mauffette Y. 2002. Temperature and food quality effects on growth, 537 consumption and post-ingestive utilization ef.ciencies of the forest tent caterpillar Malacosoma 538 disstria (Lepidoptera: Lasiocampidae). Bulletin of Entomological Research 92: 127-136. DOI: $539 \quad 10.1079 /$ BER2002153. 
540 Liaw A., Wiener M. 2002. Classification and Regression by randomForest. R News 2: 18-22.

541 Malhi Y., Aragão LE., Galbraith D., Huntingford C., Fisher R., Zelazowski P., Sitch S., McSweeney C.,

542 Meir P. . 2009. Exploring the likelihood and mechanism of a climate-change-induced dieback of the

543 Amazon rainforest. Proceedings of the National Academy of Sciences 106: 20610-20615. DOI:

$544 \quad 10.1073 /$ pnas.0804619106.

545 Matthews S. 2005. The water vapour conductance of Eucalyptus litter layers. Agricultural and Forest

546 Meteorology 135, 73-81. DOI: 10.1016/j.agrformet.2005.10.004.

547 Mcguire LP., Boyle WA. 2013. Altitudinal migration in bats: Evidence, patterns, and drivers. Biological

$548 \quad$ Reviews 88: 767-786. DOI: 10.1111/brv.12024.

549 Meijide A., Badu CS., Moyano F., Tiralla N., Gunawan D., Knohl A. 2018. Impact of forest conversion to

550 oil palm and rubber plantations on microclimate and the role of the 2015 ENSO event. Agricultural

551 and Forest Meteorology 252: 208-219. DOI: 10.1016/J.AGRFORMET.2018.01.013.

552 Mortelliti A., Amori G., Boitani L. 2010. The role of habitat quality in fragmented landscapes: a

553 conceptual overview and prospectus for future research. Oecologia 163: 535-547. DOI:

$554 \quad 10.1007 / \mathrm{s} 00442-010-1623-3$.

555 Novotny V., Basset Y., Miller SE., Weiblen GD., Bremer B., Cizek L., Drozd P. 2002. Low host

556 specificity of herbivorous insects in a tropical forest. Nature 416: 841-844. DOI: 10.1038/416841a.

557 Olivier PI., van Aarde RJ., Lombard AT. 2013. The use of habitat suitability models and species-area

558 relationships to predict extinction debts in coastal forests, South Africa. Diversity and Distributions

559 19: 1353-1365. DOI: 10.1111/ddi.12099.

560 Pettorelli N., Wegmann M., Skidmore A., Muecher S., Dawson TP., Fernandez M., Lucas R., Schaepman

561 ME., Wang T., O’Connor B., Jongman RHG., Kempeneers P., Sonnenschein R., Leidner AK.,

562 Boehm M., He KS., Nagendra H., Dubois G., Fatoyinbo T., Hansen MC., Paganini M., de Klerk

563 HM., Anser GP., Kerr JT., Estes AB., Schmeller DS., Heiden U., Rocchini D., Pereira HM., Turak

564 E., Fernandez N., Lausch A., Cho MA., Alcaraz-Segura D., McGeoch MA., Turner W., Mueller A.,

565 St-Louis V., Penner J., Vihervaara P., Belward A., Reyers B., Geller GN. 2016. Framing the concept 
of satellite remote sensing essential biodiversity variables: challenges and future directions. Remote Sensing in Ecology and Conservation 2: 122-131. DOI: 10.1002/rse2.15

Pfeifer M. 2015. Manual to measure and model leaf area index and its spatial varaibility on local and 569 landscape scale. Figshare. Fileset https://doi.org/10.6084/m9.figshare.5684182.v1.

570 Pfeifer M., Gonsamo A., Disney M., Pellikka P., Marchant R. 2012. Leaf area index for biomes of the

571 Eastern Arc Mountains: Landsat and SPOT observations along precipitation and altitude gradients.

572 Remote Sensing of Environment 118: 103-115. DOI: 10.1016/j.rse.2011.11.009.

573 Pfeifer M., Kor L., Nilus R., Turner E., Cusack J., Lysenko I., Khoo M., Chey VK., Chung AC., Ewers RM. 2016. Satellites map the structure of Borneo's tropical forests across a degradation gradient. Remote Sensing of Environment 176: 84-97. DOI: 10.1016/j.rse.2016.01.014.

576

577

578

579

580

581

582

583

584

585

586

587

588

589

590

Pfeifer M., Lefebvre V., Peres CAA., Banks-Leite C., Wearn OR., Marsh CJ., Butchart SHM., ArroyoRodriguez V., Barlow J., Cerezo A., Cisneros L., D’Cruze N., Faria D., Hadley A., Harris SM., Klingbeil BT., Kormann U., Lens L., Medina-Rangel GF., Morante-Filho JC., Olivier P., Peters SL., Pidgeon A., Ribeiro DB., Scherber C., Schneider-Maunoury L., Struebig M., Urbina-Cardona N., Watling JI., Willig MR., Wood EM., Ewers RM. Creation of forest edges has a global impact on forest vertebrates. Nature 551: 187-191. DOI: 10.1038/nature24457.

Potter KA., Arthur Woods H., Pincebourde S. 2013. Microclimatic challenges in global change biology. Global Change Biology 19: 2932-2939. DOI: 10.1111/gcb.12257.

Qi J., Chehbouni A., Huete AR., Kerr YH., Sorooshian S. 1994. A modified soil adjusted vegetation index. Remote Sensing of Environment 48: 119-126. DOI: 10.1016/0034-4257(94)90134-1.

R Core Team. 2018. R: A language and environment for statistical computing. R Foundation for Statistical Computing, Vienna, Austria. URL https://www.R-project.org/.

Rae DA., Armbruster WS., Edwards ME., Svengård-Barre M. 2006. Influence of microclimate and species interactions on the composition of plant and invertebrate communities in alpine northern Norway. Acta Oecologica 29: 266-282. DOI: 10.1016/J.ACTAO.2005.11.007.

591 Retana J., Cerdá X. 2000. Patterns of diversity and composition of Mediterranean ground ant 
592 communities tracking spatial and temporal variability in the thermal environment. Oecologia 123:

593 436-444. DOI: $10.1007 / \mathrm{s} 004420051031$.

594 Ridler T., Calvard S. 1978. Picture thresholding using an iterative selection method. IEEE transactions on

595 Systems, Man and Cybernetics 8: 630-632. DOI: 10.1109/TSMC.1978.4310039.

596 Rodgers DJ., Kitching RL. 1998. Vertical stratification of rainforest collembolan (Collembola: Insecta)

597 assemblages: description of ecological patterns and hypotheses concerning their generation.

598 Ecography 21: 392-400. DOI: 10.1111/j.1600-0587.1998.tb00404.x.

599 Rolo V., Olivier PI., Pfeifer M., van Aarde RJ. 2017. Functional diversity mediates contrasting direct and

600 indirect effects of fragmentation on below- and above-ground carbon stocks of coastal dune forests.

601 Forest Ecology and Management 407: 174-183. DOI: 10.1016/j.foreco.2017.10.059.

602 Royo AA., Collins R., Adams MB., Kirschbaum C., Carson WP. 2010. Pervasive interactions between

603 ungulate browsers and disturbance regimes promote temperate forest herbaceous diversity. Ecology

604 91: 93-105. DOI: 10.1890/08-1680.1.

605 Schulze CH., Linsenmair KE., Fiedler K. 2001. Understorey versus canopy: Patterns of vertical

606 stratification and diversity among Lepidoptera in a Bornean rain forest. In: Plant Ecology. Springer,

607 Dordrecht, 133-152. DOI: 10.1023/A:1017589711553.

608 Sekercioglu, C.H., Loarie, S.R., Oviedo Brenes, F., Ehrlich, P.R., Daily, G.C. 2007. Persistence of Forest

609 Birds in the Costa Rican Agricultural Countryside. Conservation Biology 21: 482-494. DOI:

$610 \quad 10.1111 / \mathrm{j} .1523-1739.2007 .00655 . x$.

611 Senior RA., Hill JK., del Pliego PG., Goode LK., Edwards DP. 2017 A pantropical analysis of the

612 impacts of forest degradation and conversion on local temperature. Ecology and Evolution 7: 7897-

613 7808. DOI: $10.1002 /$ ece3.3262.

614 Senior RA., Hill JK., Benedick S., Edwards DP. 2018. Tropical forests are thermally buffered despite

615 intensive selective logging. Global Change Biology 24: 1267-1278. DOI: 10.1111/gcb.13914.

616 Shirima DD., Pfeifer M., Platts PJ., Totland Ø., Moe SR. 2015. Interactions between canopy structure and

617 herbaceous biomass along environmental gradients in moist forest and dry miombo woodland of 
618 Tanzania. PLoS One 10: e0142784. DOI: 10.1371/journal.pone.0142784.

619 Stork NE., Grimbacher PS. 2006. Beetle assemblages from an Australian tropical rainforest show that the 620 canopy and the ground strata contribute equally to biodiversity. Proceedings. Biological sciences 621 273: 1969-75. DOI: 10.1098/rspb.2006.3521.

622 Suggitt AJ., Gillingham PK., Hill JK., Huntley B., Kunin WE., Roy DB., Thomas CD.. 2011. Habitat 623 microclimates drive fine-scale variation in extreme temperatures. Oikos 120: 1-8. DOI:

$624 \quad 10.1111 /$ j.1600-0706.2010.18270.x.

625 Tucker CJ. 1979. Red and photographic infrared linear combinations for monitoring vegetation. Remote 626 Sensing of Environment 8: 127-150. DOI: 10.1016/0034-4257(79)90013-0.

627 Von Arx G., Dobbertin M., Rebetez M. 2012. Spatio-temporal effects of forest canopy on understory 628 microclimate in a long-term experiment in Switzerland. Agricultural and Forest Meteorology 166: 629 144-155. DOI: 10.1016/j.agrformet.2012.07.018.

630 Wickham H. 2016. ggplot2: Elegant Graphics for Data Analysis. Springer-Verlag New York.

631 Weiss M., Baret F. 2010. CAN-EYE. EMMAH laboratory (Mediterranean environment and agro-hydro 632 system modelisation), National Institute of Agricultural Research (INRA), French (2010) 633 https://www6.paca.inra.fr/can-eye/. Last accessed 15/10/2018, 634 Wood SN. 2017. Generalized Additive Models: an introduction with R (2nd edition), CRC. R package 635 version 1.8. https://cran.r-project.org/web/packages/mgcv/index.html.

636 Wyk AE van., Smith GF. 2001. Regions of floristic endemism in Southern Africa: a review with emphasis 637 on succulents. ISBN 1919766189. Umdaus Press, Hatfield, South Africa.

638 Zvoleff A. 2016. glcm: Calculate Textures from Grey-Level Co-Occurrence Matrices (GLCMs). R 639 package version 1.6.1. https://CRAN.R-project.org/package=glcm.

640

641 


\section{Figure 1}

Location of fieldwork in Kwa Zulu-Natal province, South Africa.

In April 2018, plots were set up in five main habitat types (i.e. natural grassland, open bushland, natural forests, edges of natural forests and timber plantations comprising Eucalytpus species) located along 11 linear transects: six transects across forest - edge -grassland (T01, T02, T07-T10), four transects across forest - edge -plantation (T03-T06) and one transect across forest -edge - grassland - bush (T11). Each transect comprised three plots (one per habitat type) except for T11, which comprised five plots. ( A-C ) A typical transect encompassing natural grassland (A), the forest edge (B) and the forest (C). ( D ) Zoom into the transects sampled at the northern boundary of Ngoye forest. The dense forest (C) is shown in dark red and is clearly delineated from the natural grassland (A). The map is a false colour composite using RapidEye imagery at $5 \mathrm{~m}$ pixel resolution. (E) Location of sample sites within the study region. In the 2018 plots, we sampled $N D V I_{\text {down }}$ and Thermal ground as well as and canopy LAI and FCover (the latter was not measured in grassland plots, as they did not feature trees). We increased sampling effort for the development of canopy structure maps from Landsat data (see Fig. 6). Canopy structure was measured at an additional 17 forest plots and 7 tree plantation plots in 2018. We also included an additional 52 forest plots and 11 needle leaved plantation plots measured in 2015 (E). 

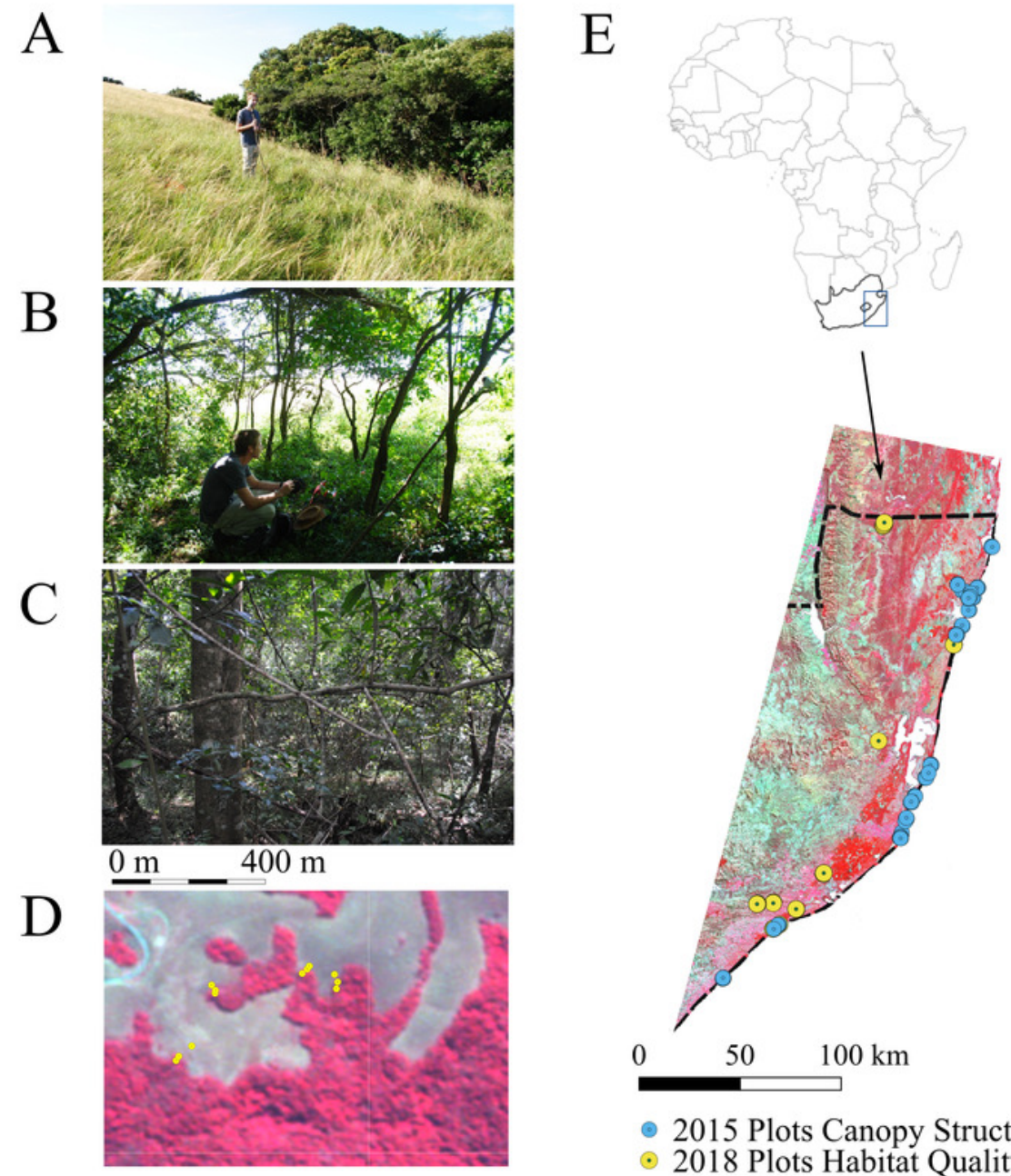

- 2015 Plots Canopy Structure

• 2018 Plots Habitat Quality 
Figure 2 (on next page)

Sampling design for habitat attributes measured during fieldwork.

(A) Plot sampling. We acquired $N D V I_{\text {up }}, N D V I_{\text {down }}$ and Thermal ground images at five sample points (S1 - S5) located within a $5 \mathrm{~m} \times 5 \mathrm{~m}$ subplot (pink shade) in the centre of each plot (20 m x $20 \mathrm{~m}$ ). We acquired fisheye images at 12 sample points (S1 - S12) per plot. FCover is estimated from the fisheye images for each sample point, while $L A l$ is estimated at plot level (one per plot). ( B) Plot location. Plots were located along linear transects stretching from natural forests across the forest edge to other habitats. Darker shades indicate core areas of respective habitats. 
PeerJ

A

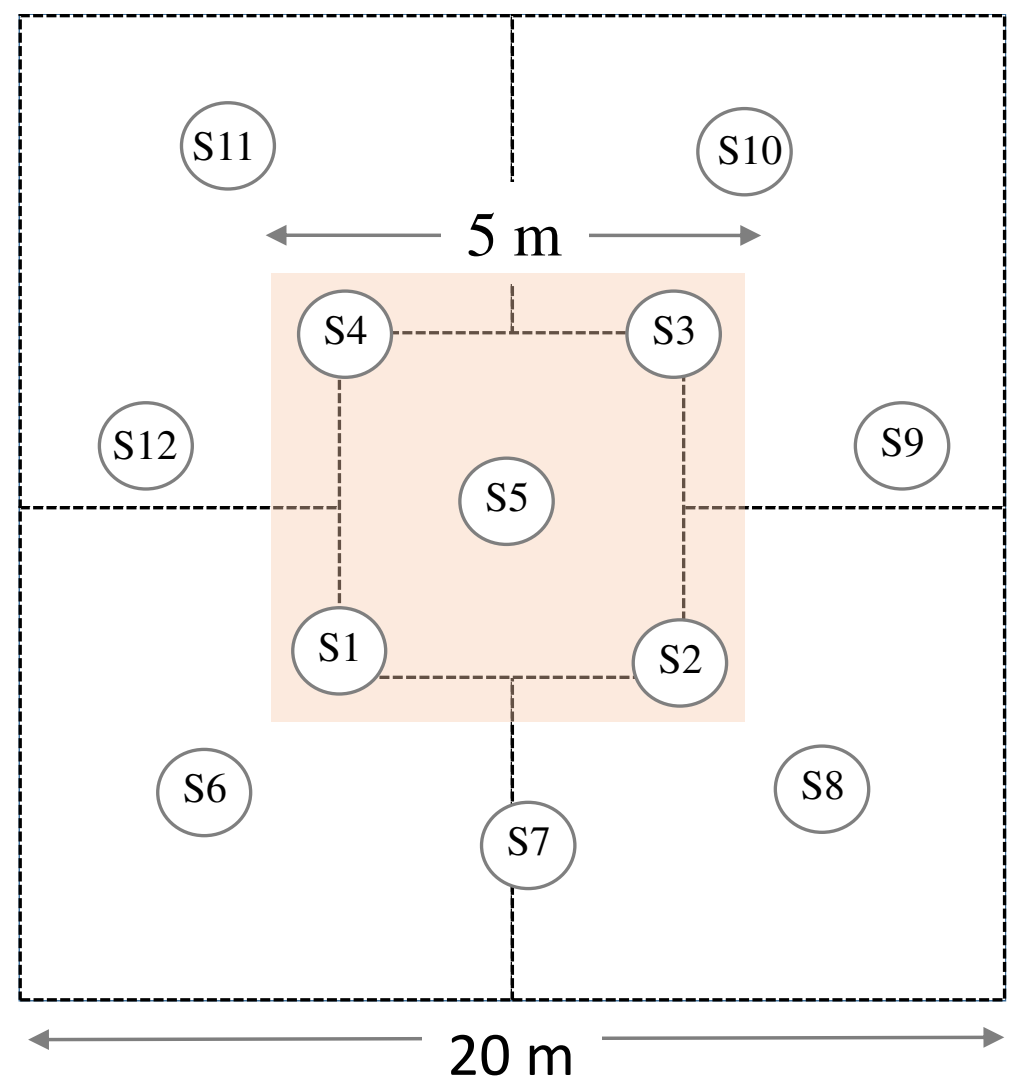

Thermal, $\mathrm{NDVI}_{\mathrm{up}}, \mathrm{NDVI}_{\text {down }} \&$ fisheye data

Fisheye data
B

\section{Forest habitat}

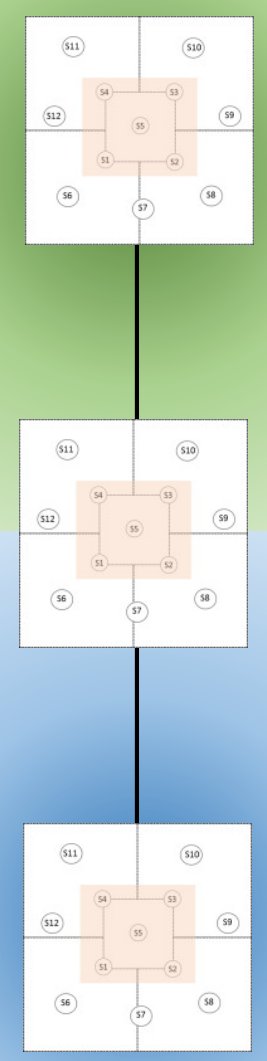

Matrix habitat 


\section{Figure 3 (on next page)}

Habitat attributes and their variation within and across habitat types.

Habitat attributes and their variation within and across habitat types. Sample size differed between habitats. (A) NDVI down $: 144$ points sampled across 29 plots (Grassland: 35 points from 7 plots, Bush: 5 points in 1 plots Edge: 54 points in 11 plots, Forest: 35 points in 7 plots and Plantation: 15 points from 3 plots). (B) Thermal ground : 169 points sampled across 34 plots (Grassland: 30 points from 6 plots, Bush: 5 points in 1 plot, Edge: 54 points in 11 plots, Forest: 60 points in 12 plots and Plantation: 20 points from 4 plots). (C) $N D V I_{u p}$ : 139 points sampled across 28 plots (Bush: 5 points in 1 plots, Edge: 54 points in 11 plots, Forest: 60 points in 12 plots and Plantation: 20 points from 4 plots). (D) LAI : data are only estimated at plot level and hence shown for 1 bush plot, 11 edge plots, 7 woodland plots, 17 forest plots, and 4 plantation plots. (E) FCover : 528 points sampled across 40 plots (Bush: 15 points in 1 plots, Edge: 155 points in 11 plots, Woodland: 68 points in 7 plots, Forest: 230 points in 17 plots and Plantation: 60 points from 4 plots). 


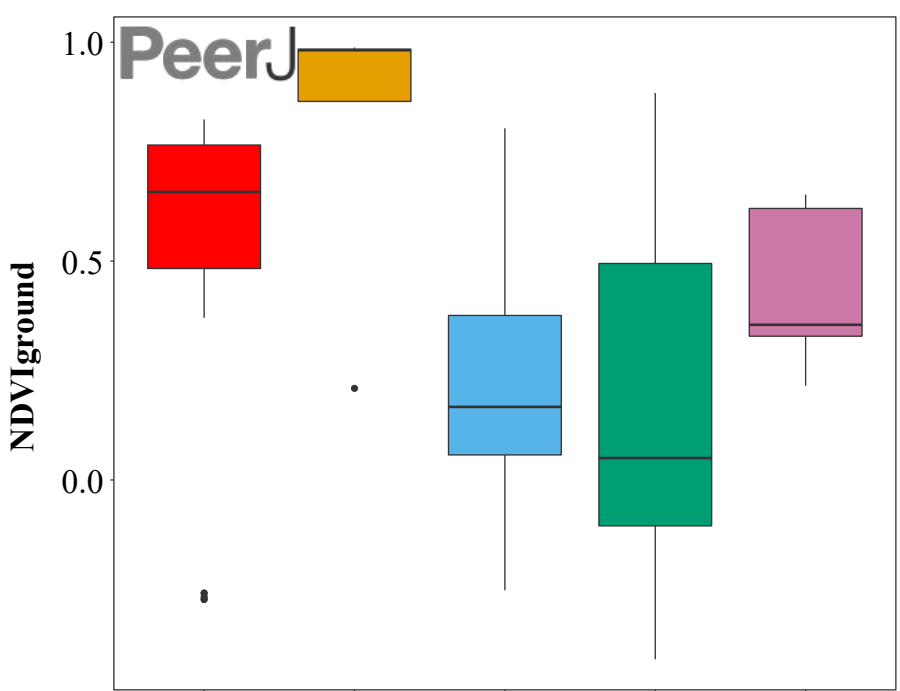

Grassland Bush Edge Forest Plantation
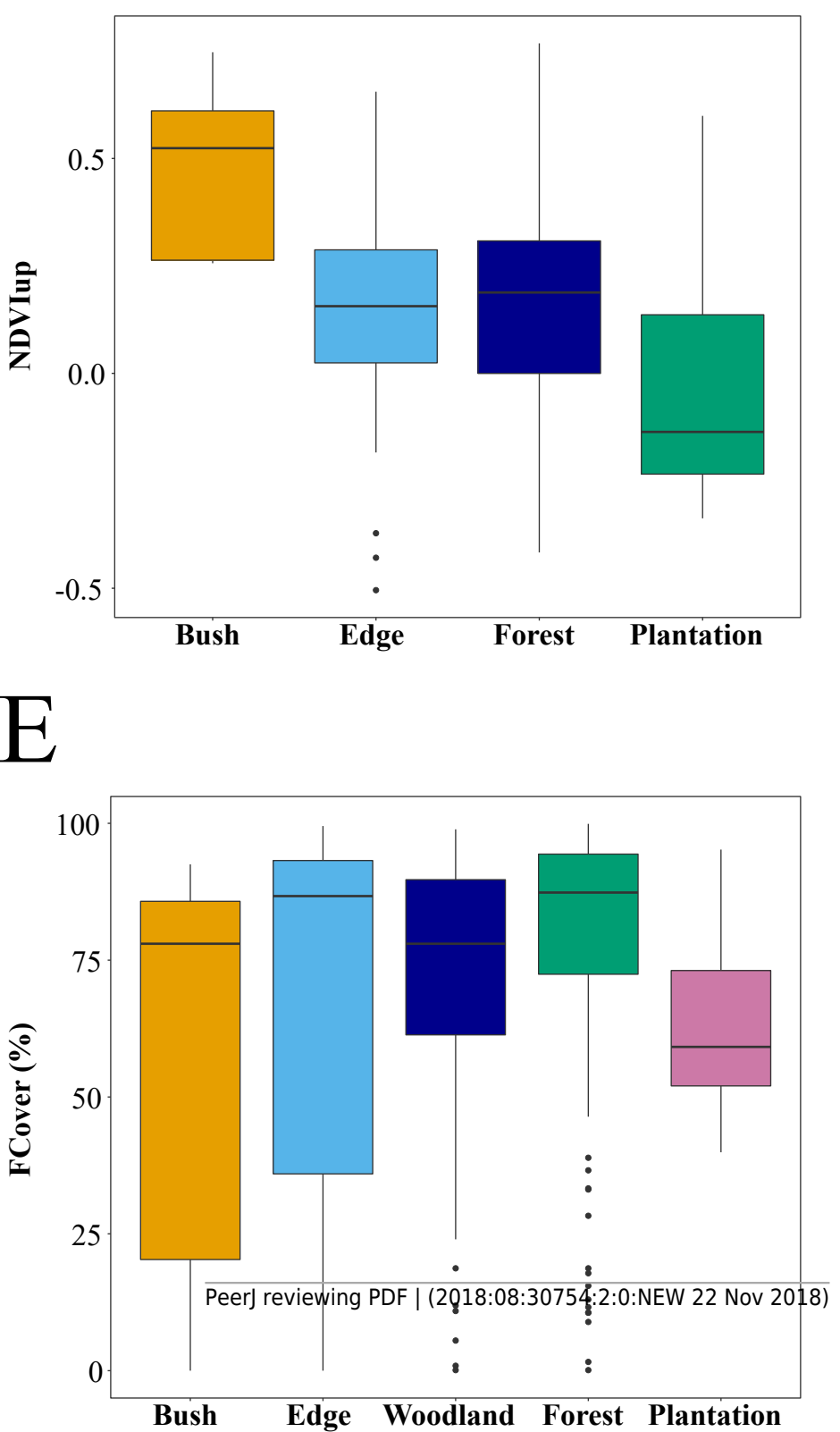

Bush

Edge Woodland Forest Plantation
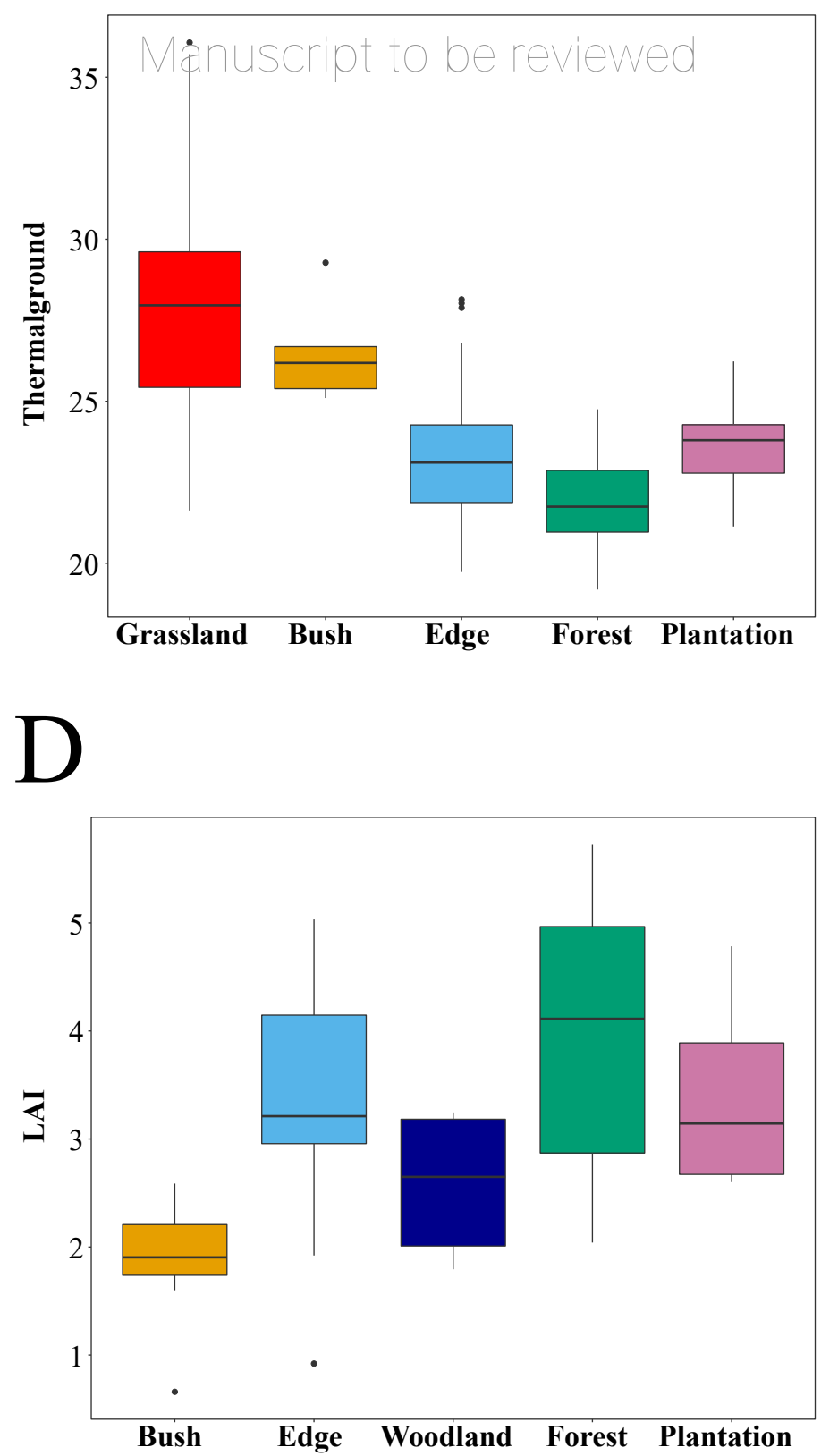


\section{Figure 4 (on next page)}

Habitat attributes aggregated at plot scale and their inter-relationships.

We plotted habitat attributes for each sample point (grey dots) and aggregated at plot level for each habitat type. We used general additive and linear modelling (GAM and LM) to test whether Thermal ${ }_{\text {ground }}$ increases with $N D V I_{\text {down }}$, and for each whether they decline with attributes indicating increasing canopy closure. The graphs show the better fitting model for each relationship visualised as smoothed conditional means (grey line) with a $95 \%$ confidence interval (grey shaded band). Model fits shown with *** indicating $P<0.001$, ** indicating $P<0.01$ and * indicating $P<0.05$. Model details are shown in Table 2. (A) The decline of $N D V I_{\text {down }}$ with increasing FCover followed a nonlinear pattern with the rate of decline increasing once canopy closure increases to more than 40-50\% (GAM, N $=29, R^{2}{ }_{\text {adj }}$ $\left.=0.28^{* *}\right)$. (B) Thermal $l_{\text {ground }}$ declined linearly with increasing canopy closure $(L M, N=34$, $\left.R^{2}{ }_{a d j}=0.51 * * *\right)$. The model suggests that for each increase in canopy closure by $20 \%$, Thermal $I_{\text {ground }}$ would decline by $1.2^{\circ}$ Celsius. (C) $N D V I_{\text {down }}$ displayed a non-linear convex dependency on canopy greenness (GAM, $N=29, R^{2}{ }_{a d j}=0.39 * *$ ). For values of $N D V I_{u p}$ above 0.0,NDVI down increased with increasing $N D V l_{\text {up }}$, for values of $N D V I_{\text {up }}$ below 0.0, $N D V I_{\text {down }}$ increased with declining canopy greenness. (D) Thermal $\left.\right|_{\text {ground }}$ increased significantly with increasing $N D V I_{\text {down }}\left(L M, N=28, R^{2}{ }_{a d j}=0.21^{* *}\right)$. We highlighted plots for

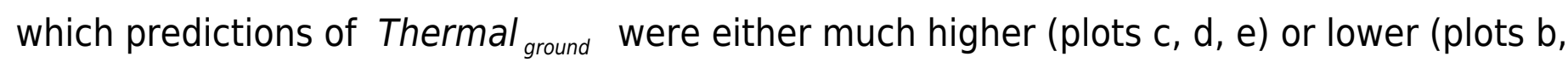
e) than expected from the models. Grassland plots (red letters): Plot a was measured at midday during a hot and sunny day, whilst plot b was measured at Ngoye but a couple of hours earlier than plot a. Plot c measured at Enseleni Nature Reserve, featuring patches of high grass and bare soil, and plot $d$ was located in an area with high grazing pressure at Sodwana Bay. Forest plot (green letter): Plot e was measured at Enseleni before midday. 

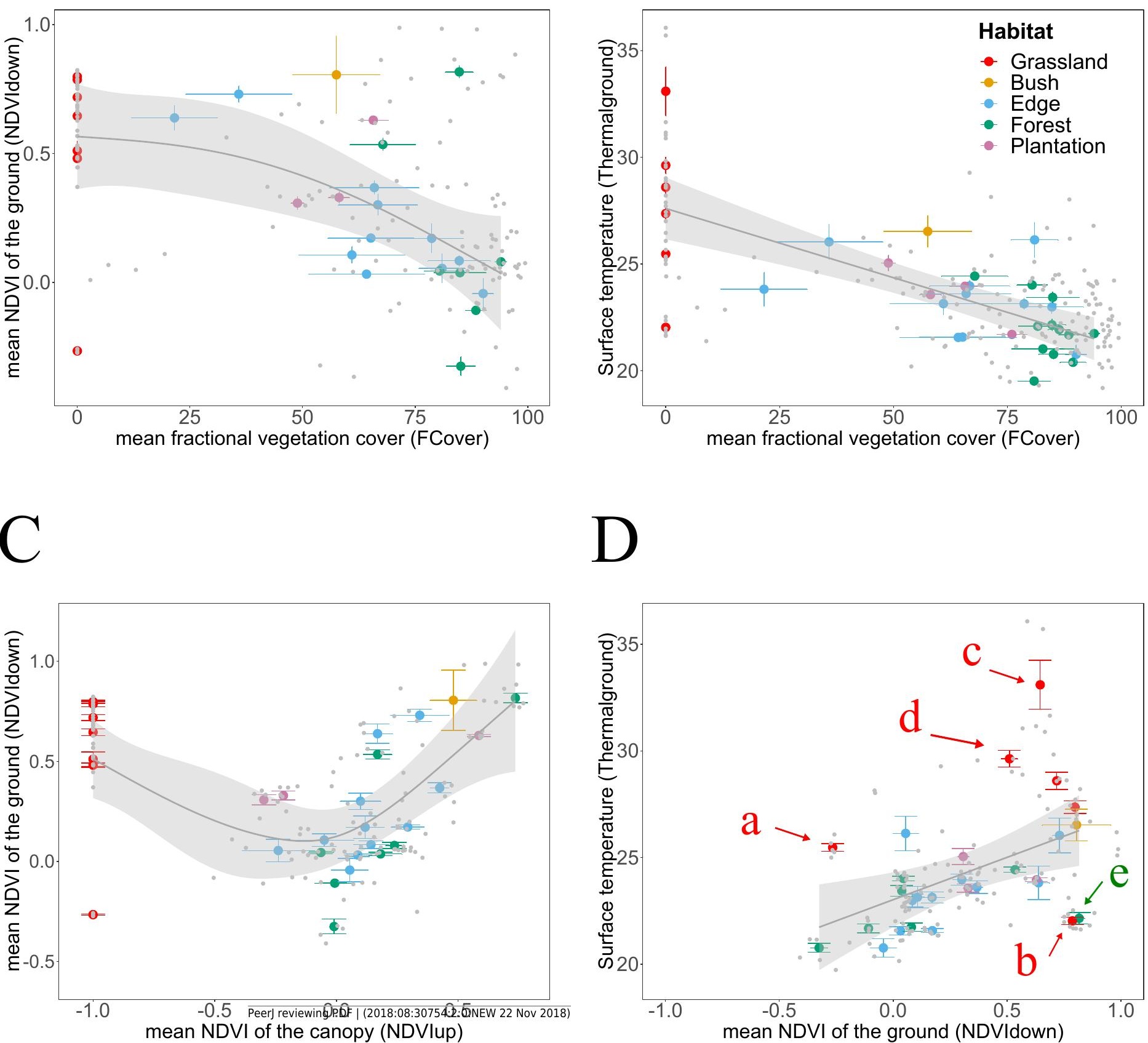


\section{Figure 5 (on next page)}

Canopy LAI dependencies of Thermal $\left.\right|_{\text {ground }}$ and $N D V I_{\text {down }}$.

We plotted habitat attributes for each plot and habitat type. We used general additive and linear modelling (GAM and LM) to test for significant relationships. The graphs show the better fitting model for each relationship visualised as smoothed conditional means (grey line) with a $95 \%$ confidence interval (grey shaded band). Model fits shown with *** indicating $P<0.001$, ** indicating $P<0.01$ and $*$ indicating $P<$ 0.05. Model details are shown in Table 2. (A) $N D V I_{\text {down }}$ declined significantly with increasing canopy leaf area $\left(L M, N=29, R^{2}{ }_{a d j}=0.20 * *\right)$. (B) Thermal ground declined significantly with increasing canopy leaf area $\left(\mathrm{LM}, \mathrm{N}=34, R^{2}{ }_{\text {adj }}=0.52 * * *\right)$. 

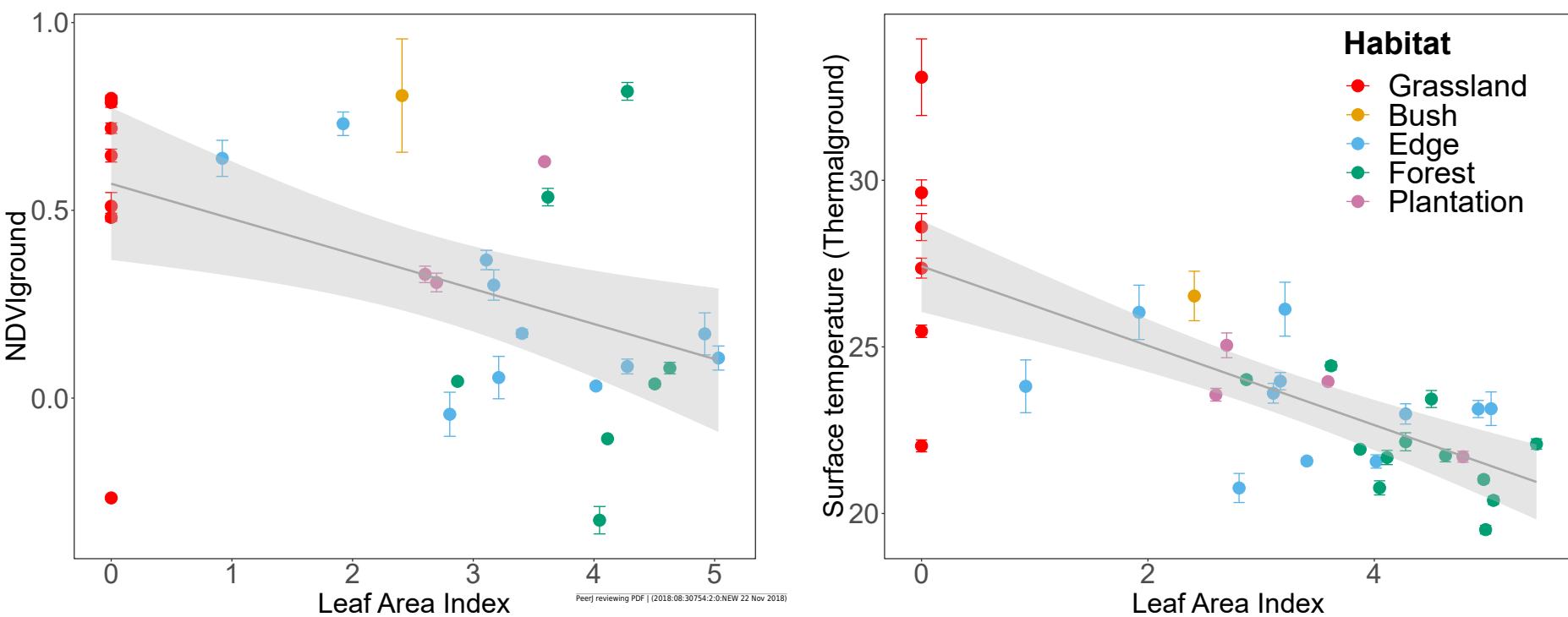


\section{Figure 6 (on next page)}

Zoom into maps of $L A I$ and Thermal $I_{\text {ground }}$ produced for the study region.

The zoom shows Ngoye forest, an ancient scarp forest fragment located around $10 \mathrm{~km}$ away from the coast. (A) We mapped $L A I$ based on texture and spectral indices derived from Landsat 8 reflectance data (see Table 5 for model details). (B) We used the LAI maps with the statistical models described in Fig. 5 and Table 2 to map Thermal ground . (C) The ancient forests are directly bordered by natural grasslands along large parts of the northern and southern edge of the forest ( E, G ). However, the landscape changes dramatically in the surroundings, with homesteads scattered in hilly areas ( D ) and sugarcane growing on small-holder farms and in lowland industrial plantations ( $\mathbf{H}$ ). Timber plantations ( $\mathbf{F}$ ) can be found along the coast and slightly further inland. 


\section{A}

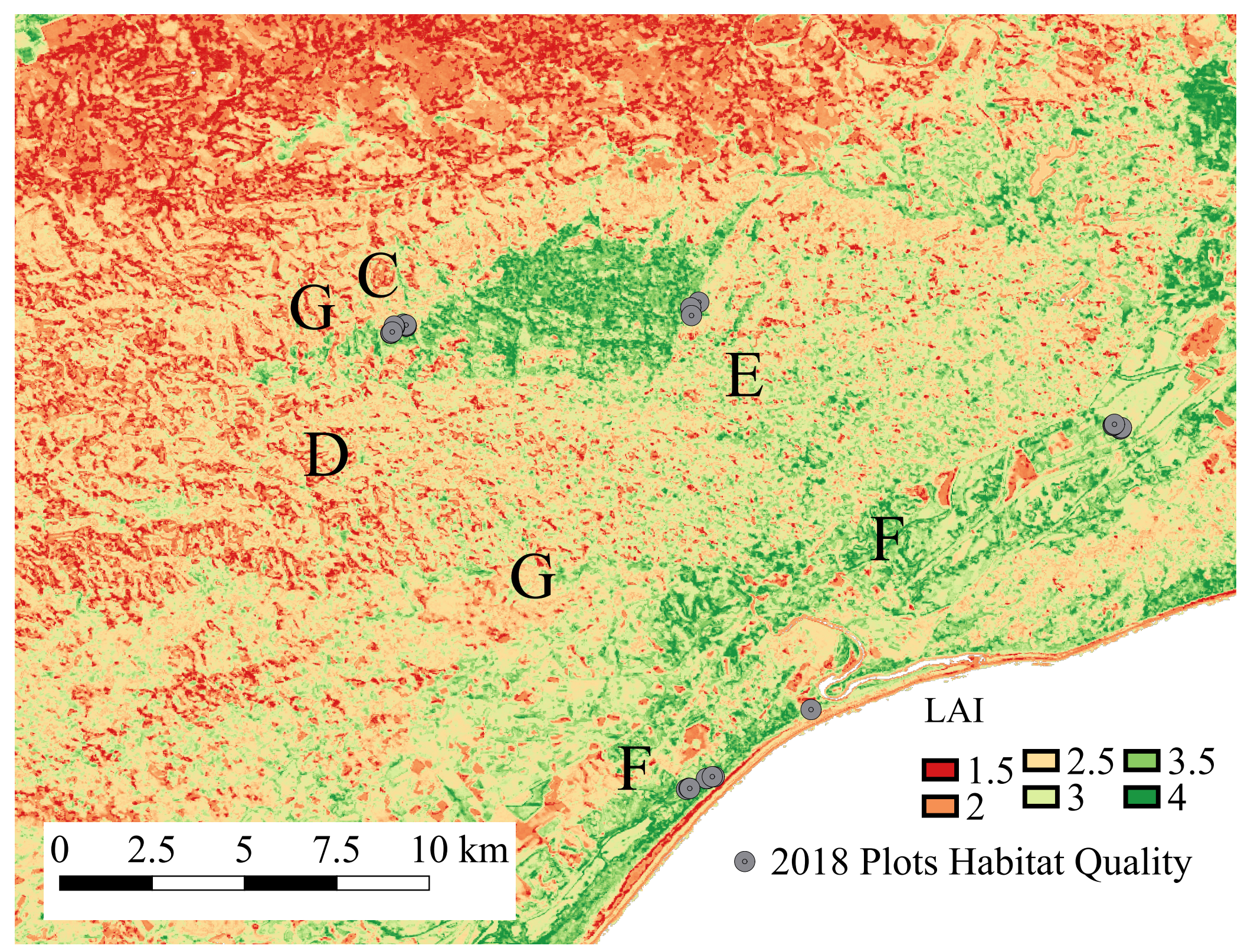

C

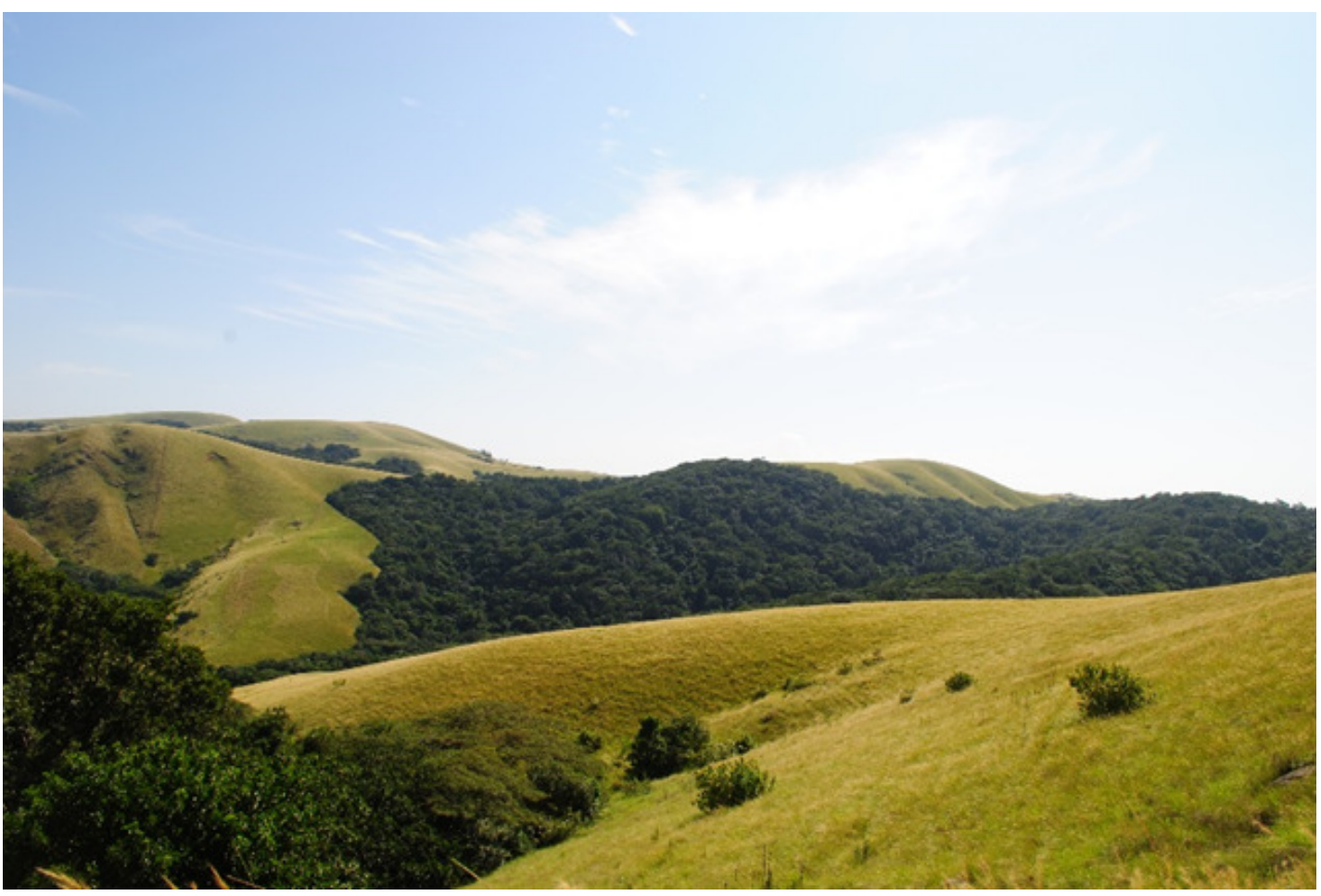

F

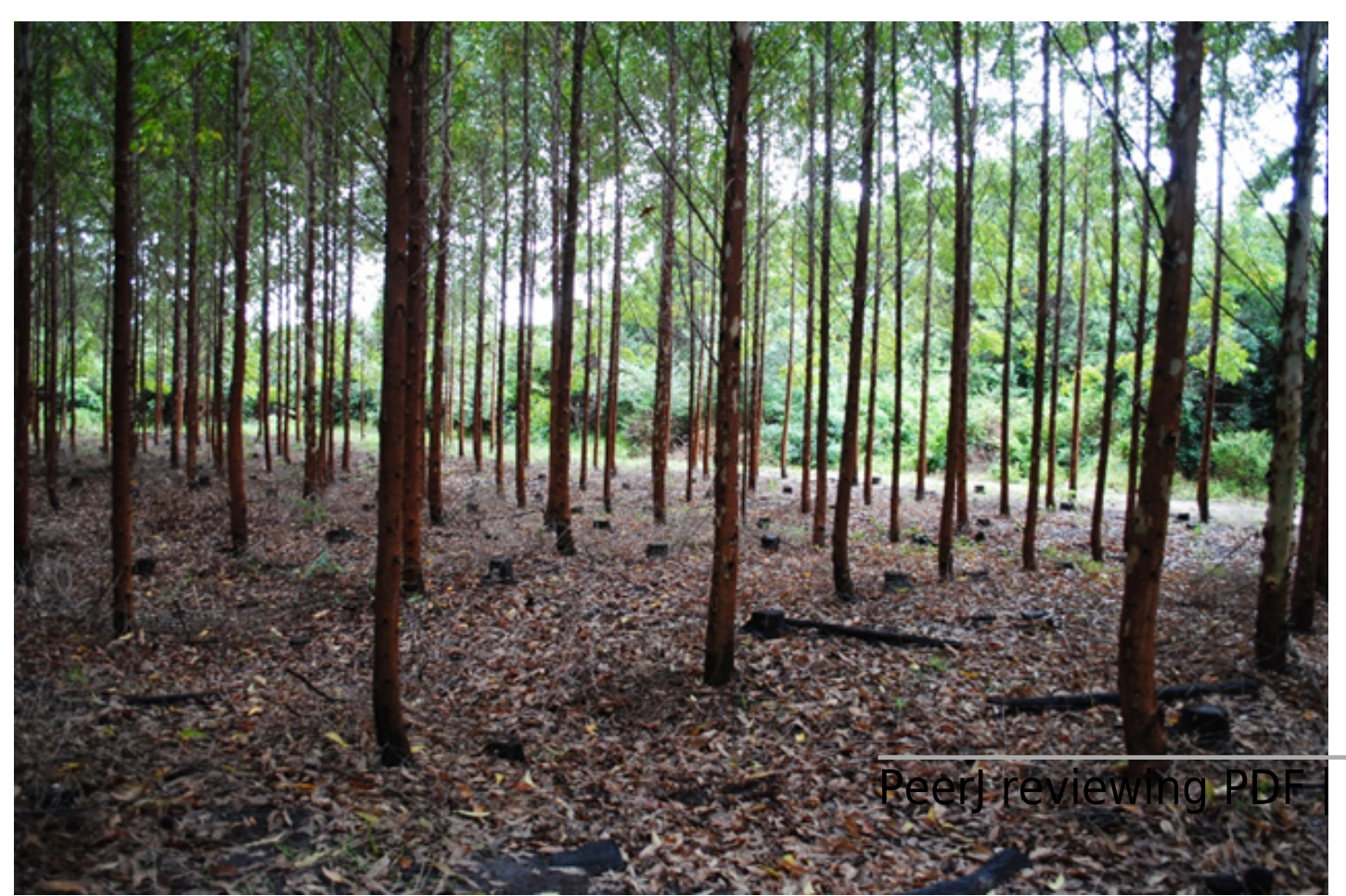

G
B

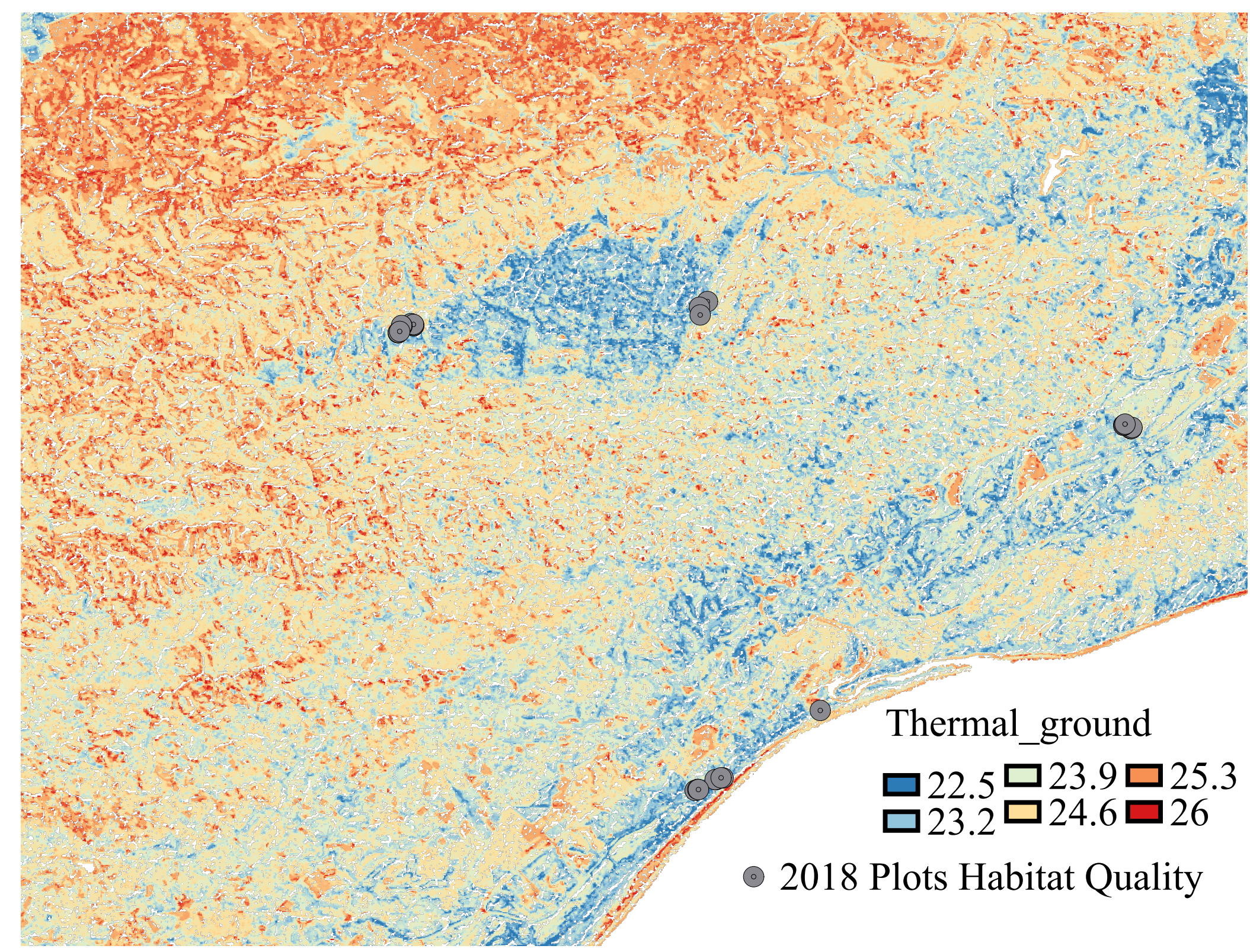

E
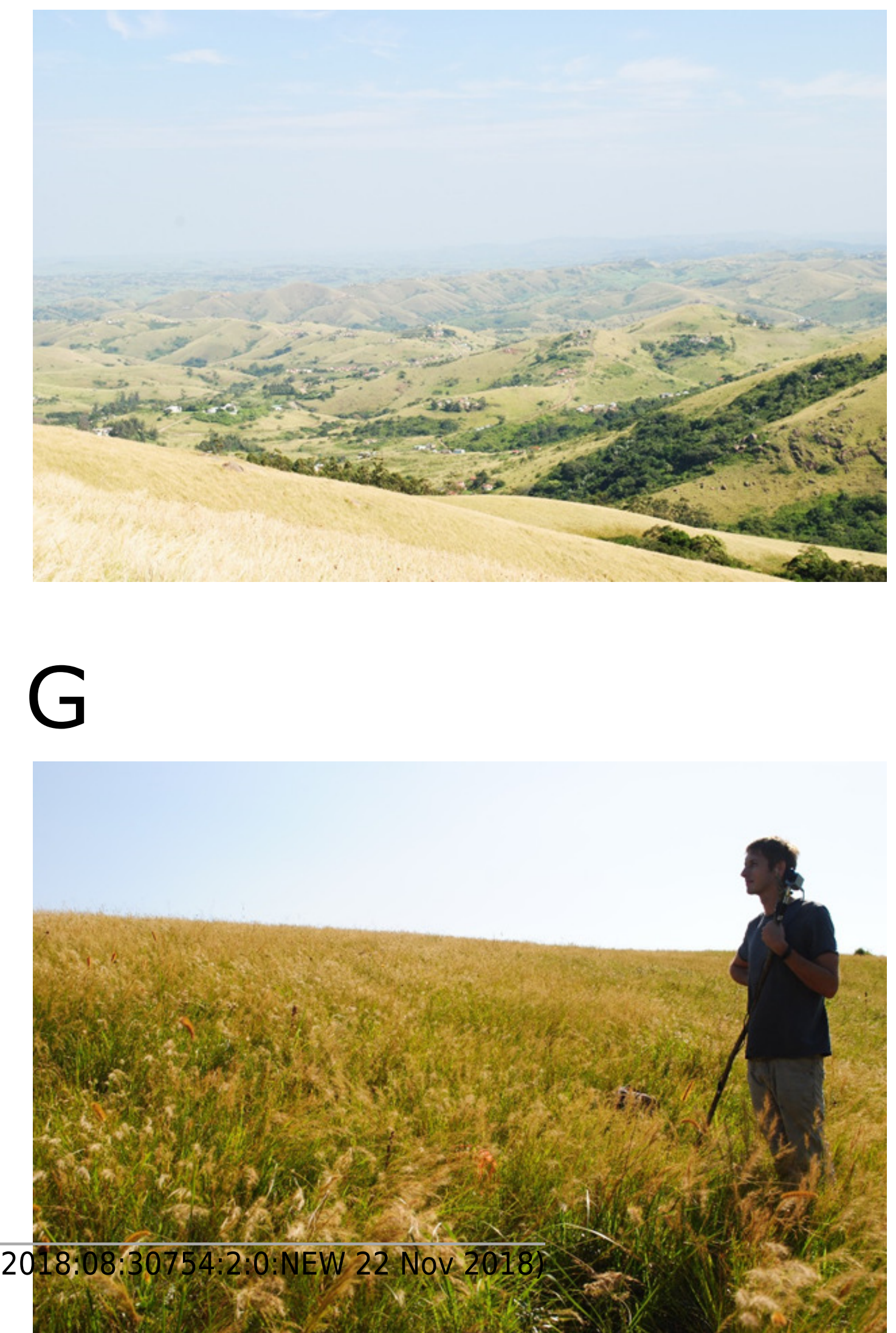

$\mathrm{H}$
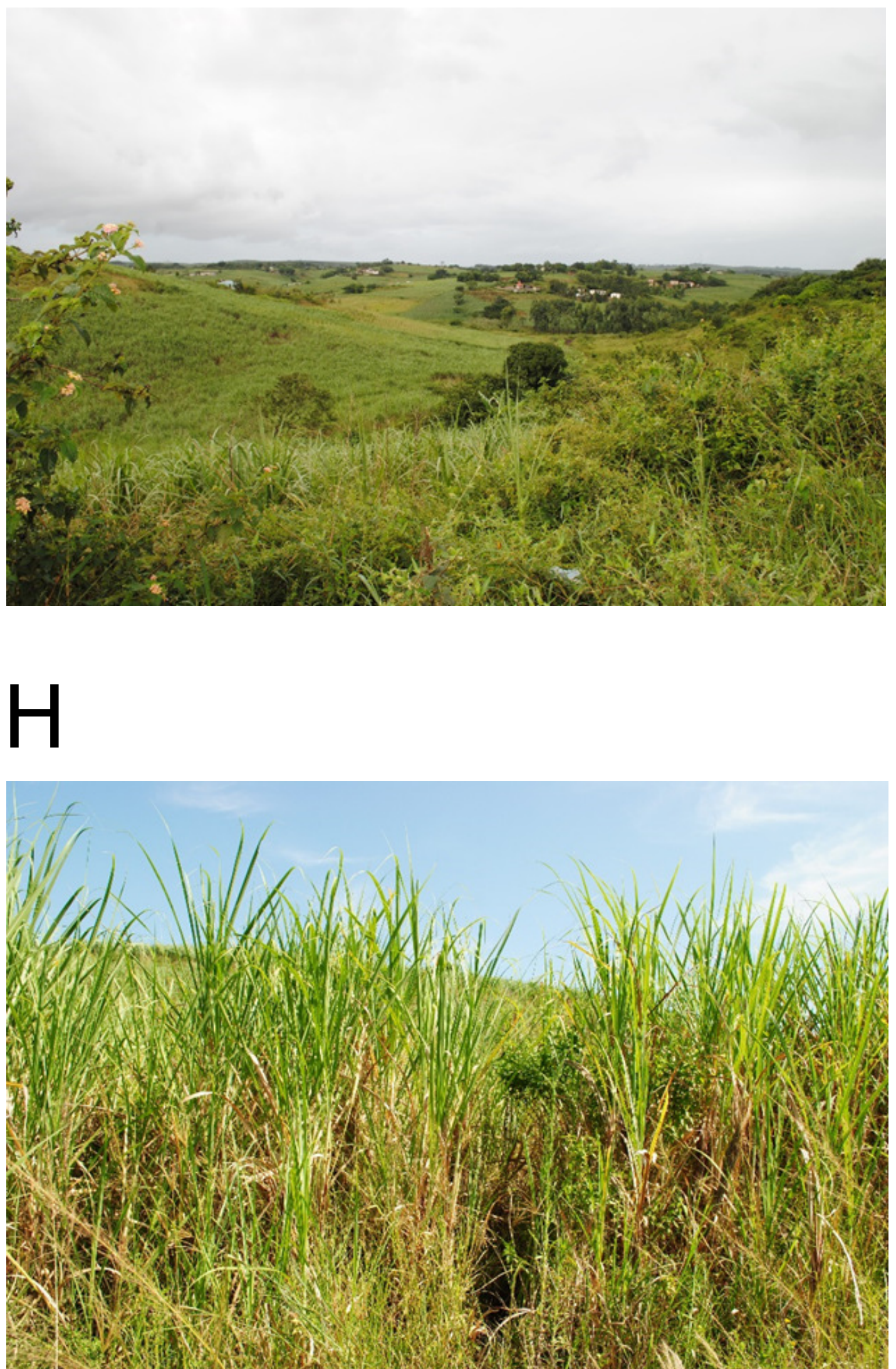


\section{Table $\mathbf{1}$ (on next page)}

Processing steps involved when analysing NDVI and thermal imagery.

RED - Red reflectance values. NIR - Near-Infrared reflectance values. 


\begin{tabular}{|c|c|}
\hline Metric & Processing steps \\
\hline$\overline{N D V I_{u p}}$ & $\begin{array}{l}\text { 1. Read *jpg image, which consists of three bands } \\
\text { 2. Extract band } 1 \text { (RED) and band } 3 \text { (NIR) } \\
\text { 3. Compute NDVI as (NIR-RED)/(NIR+RED) } \\
\text { 4. Compute statistics: mean, median, minimum, maximum and standard deviation }\end{array}$ \\
\hline$N D V I_{d o w n}$ & $\begin{array}{l}\text { 1. Read *jpg image, which consists of three bands } \\
\text { 2. Extract band } 1 \text { (RED) and band } 3(\mathrm{NIR}) \\
\text { 3. Compute NDVI as (NIR-RED)/(NIR+RED) } \\
\text { 4. Delineate region of interest in image (subset) using the clearly visible boundary } \\
\text { 5. Compute statistics for subset: mean, median, minimum, maximum, number of } \\
\text { pixels, and standard deviation }\end{array}$ \\
\hline Thermal $_{\text {ground }}$ & $\begin{array}{l}\text { 1. Read } * \operatorname{csv} \text { file and plot as matrix } \\
\text { 2. Delineate region of interest on the displayed file using the clearly visible } \\
\text { boundary using the same extent of } 150 \times 150 \text { cells } \\
\text { 3. Compute statistics for each subset: mean, median, minimum, maximum, number } \\
\text { of values and standard deviation }\end{array}$ \\
\hline
\end{tabular}

2 


\section{Table 2 (on next page)}

Interrelationships between habitat attributes at plot level.

We compared general additive models (GAM) to linear models (LM) and reported on the variance explained by the model (adjusted R-squared, $\mathrm{R}_{\text {adjust }}$ ), the Intercept and the estimate for the smoothing term (ST) or coefficients. Models were fit to data aggregated at the level of plots using the 'average' function. Model details are shown with *** indicating $P<0.001$, ** indicating $P<0.01$ and $*$ indicating $P<0.05$. Canopy $L A l$ and FCover were set to 0 for grassland plots and $N D V I_{u p}$ was set to -1 acknowledging that there were no trees present. We tested whether including grassland plots in the modelling would significantly affect model outcomes (With grass; Without grass). Models chosen for reporting are highlighted by grey shaded cells. 
1

\begin{tabular}{|c|c|c|c|c|c|c|c|}
\hline & & \multicolumn{3}{|c|}{ With grass } & \multicolumn{3}{|c|}{ Without grass } \\
\hline & & GAM & LM & $\mathbf{N}$ & GAM & LM & $\mathbf{N}$ \\
\hline \multirow{3}{*}{ Thermal $_{\text {ground }} \sim N D V I_{\text {dow }}$} & $\mathrm{R}_{\text {adjust }}^{2}$ & $0.21 * *$ & $0.21 * *$ & 28 & $0.30 * *$ & $0.31 * *$ & 22 \\
\hline & Intercept & $24.3 * * *$ & $23.02 * * *$ & & $23.4 * * *$ & $22.6 * * *$ & \\
\hline & ST/Coefficient & 1 & $3.97 * * *$ & & 1 & $3.06 * *$ & \\
\hline \multirow{3}{*}{ Thermal $_{\text {ground }} \sim F$ Cover } & $\mathrm{R}_{\text {adjust }}^{2}$ & $0.51 * * *$ & $0.51 * * *$ & 34 & $0.31 * *$ & $0.30 * *$ & 28 \\
\hline & Intercept & $23.7 * * *$ & $27.6 * * *$ & & $22.9 * * *$ & $27.2 * * *$ & \\
\hline & ST/Coefficient & 1 & $-0.06 * * *$ & & 1.4 & $-0.06 * *$ & \\
\hline \multirow[t]{3}{*}{ Thermal $_{\text {ground }} \sim L A I$} & $\mathrm{R}_{\text {adjust }}^{2}$ & $0.52 * * *$ & $0.52 * * *$ & 34 & $0.35 * * *$ & $0.35 * * *$ & 28 \\
\hline & Intercept & $23.7 * * *$ & $27.4 * * *$ & & $22.9 * * *$ & $26.6 * * *$ & \\
\hline & ST/Coefficient & 1 & $-1.19 * * *$ & & 1 & $-1.0 * * *$ & \\
\hline \multirow[t]{3}{*}{ Thermal $_{\text {ground }} \sim N D V I_{u p}$} & $\mathrm{R}_{\text {adjust }}^{2}$ & $0.38 * * *$ & $0.30 * * *$ & 34 & \multirow{3}{*}{\multicolumn{2}{|c|}{ not significant }} & 28 \\
\hline & Intercept & $23.7 * * *$ & $23.6 * * *$ & & & & \\
\hline & ST/Coefficient & 1.98 & $-3.20 * * *$ & & & & \\
\hline \multirow[t]{3}{*}{$N D V I_{\text {down }} \sim F$ Cover } & $\mathrm{R}_{\text {adjust }}^{2}$ & $0.28 * *$ & $0.24 * *$ & 29 & $0.33 * *$ & $0.33 * *$ & 22 \\
\hline & Intercept & $0.33 * * *$ & $0.60 * * *$ & & $0.26 * * *$ & $0.98 * * *$ & \\
\hline & ST/Coefficient & 1.61 & $-0.01 * *$ & & 1 & $-0.01 * *$ & \\
\hline \multirow[t]{3}{*}{$N D V I_{\text {down }} \sim L A I$} & $\mathrm{R}_{\text {adjust }}^{2}$ & $0.20 * *$ & $0.20 * *$ & 29 & $0.18^{*}$ & $0.18^{*}$ & 22 \\
\hline & Intercept & $0.33 * * *$ & $0.57 * * *$ & & $0.26 * * *$ & $0.76^{* *}$ & \\
\hline & ST/Coefficient & 1 & $-0.09 * *$ & & 1 & $-0.14^{*}$ & \\
\hline \multirow[t]{3}{*}{$N D V I_{d o w n} \sim N D V I_{u p}$} & $\mathrm{R}_{\text {adjust }}^{2}$ & $0.39 * *$ & \multirow{3}{*}{$\begin{array}{l}\text { not } \\
\text { significant }\end{array}$} & 29 & $0.51 * *$ & $0.36^{* *}$ & 22 \\
\hline & Intercept & $0.33 * *$ & & & $0.26 * * *$ & $0.15^{*}$ & \\
\hline & ST/Coefficient & 2.38 & & & 2.84 & $0.75^{* *}$ & \\
\hline
\end{tabular}

2 


\section{Table 3 (on next page)}

Interrelationships between habitat attributes at plot level.

Model details shown with *** indicating $P<0.001$, ** indicating $P<0.01$ and * indicating $P<$ 0.05 . Canopy $L A I$ and FCover were set to 0 for grassland plots and $N D V I_{u p}$ was set to -1 acknowledging that there were no trees present. Models were fit to data aggregated at the level of plots using the 'min' , 'max' and 'mean' functions respectively. LAl estimates were only derived at plot level. Bold numbers in grey shaded cells indicate that general additive models were the better fit compared to linear models. Response variables respectively were minimum, maximum and mean values of $N D V I_{\text {down }}$ and Thermal $I_{\text {ground. }}$. Numbers are adjusted Rsquared estimates for the statistical models fitted to the data. The type of the relationship (positive, negative, concave) did not change in comparison to models based on averages (see Table 2). 
1

\begin{tabular}{|c|c|c|c|c|c|c|c|}
\hline & & \multicolumn{3}{|c|}{$N D V I_{d o w n}$} & \multicolumn{3}{|c|}{ Thermal $_{\text {ground }}$} \\
\hline & & Min & Max & Mean & Min & Max & Mean \\
\hline \multirow[t]{3}{*}{$N D V I_{u p}$} & Min & $0.37 * *$ & $0.29 *$ & $0.33 * *$ & $0.42 * * *$ & $0.32 * *$ & $0.38 * * *$ \\
\hline & Max & $0.39 * *$ & $0.45 * * *$ & $0.47 * * *$ & $0.44 * * *$ & $0.34 * *$ & $0.40 * * *$ \\
\hline & Mean & $0.40 * *$ & $0.35 * *$ & $0.39 * *$ & $0.43 * * *$ & $0.32 * *$ & $0.38 * * *$ \\
\hline \multirow[t]{3}{*}{ FCover } & Min & ns & ns & ns & $0.22 * *$ & $0.25 * *$ & $0.25 * *$ \\
\hline & Max & $0.24 *$ & $0.26 *$ & $0.28 *$ & $0.50 * * *$ & $0.39 * * *$ & $0.46 * * *$ \\
\hline & Mean & $0.28 * *$ & $0.24 *$ & $0.28 * *$ & $0.50 * * *$ & $0.47 * * *$ & $0.51 * * *$ \\
\hline$L A I$ & Mean & & & $0.20 * *$ & & & $0.52 * * *$ \\
\hline
\end{tabular}

2 


\section{Table 4 (on next page)}

Effects of air temperature on modelled relationships between canopy structure attributes and Thermal ${ }_{\text {ground. }}$.

We expanded the linear models, identified as best fit predicting the response of Thermal $l_{\text {ground }}$ to either FCover or Thermal ${ }_{\text {ground }}$ (see Table 2 ) by including additional and interactive effects of air temperature $\left(T_{\text {air }}\right)$. The predictive capacity of the models improved significantly as indicated by the adjusted R-squared $\left(R_{a d j}^{2}\right)$. We estimated intercept and slope based on the derived models for selected values of $T_{\text {air }}(21,23,25,27$, and 29 degree Celsius. Model details are shown with *** indicating $P<0.001$, ** indicating $P<0.01$, * indicating $P<0.05$ and ${ }^{\text {andicating }} P<0.10$. 
1

\begin{tabular}{|c|c|c|}
\hline & Thermal $_{\text {ground }} \sim F$ Cover $* T_{\text {air }}$ & Thermal $_{\text {ground }} \sim L A I * T_{\text {air }}$ \\
\hline Intercept & 2.074357 & 3.2155 \\
\hline FCover or $L A I$ & $0.155010^{\mathrm{a}}$ & $3.0012 *$ \\
\hline$T_{a i r}$ & $0.887836^{* * *}$ & $0.8054 * * *$ \\
\hline FCover $* T_{\text {air }}$ & $-0.007211^{*}$ & $-0.1424 * *$ \\
\hline $\boldsymbol{R}_{a d j}^{2}$ & $0.73 * * *$ & $0.78 * * *$ \\
\hline$T_{a i r}=21^{\circ} \mathrm{C}$ & Intercept $=20.7$, Slope $=0.00358$ & Intercept $=21.1$, Slope $=0.0108$ \\
\hline$T_{a i r}=23^{\circ} \mathrm{C}$ & Intercept $=22.4$, Slope $=-0.01084$ & Intercept $=22.8$, Slope $=-0.274$ \\
\hline$T_{a i r}=25^{\circ} \mathrm{C}$ & Intercept $=24.3$, Slope $=-0.02527$ & Intercept $=24.5$, Slope $=-0.5588$ \\
\hline$T_{a i r}=27^{\circ} \mathrm{C}$ & Intercept $=26.0$, Slope $=-0.03969$ & Intercept $=26.2$, Slope $=-0.8436$ \\
\hline$T_{a i r}=29$ & Intercept $=27.8$, Slope $=-0.05411$ & Intercept $=27.9$, Slope $=-1.1284$ \\
\hline
\end{tabular}

2

3

4 


\section{Table 5 (on next page)}

Final models used to predict canopy attributes from Landsat spectral reflectance data and derived spectral and texture indices based on $\mathrm{N}=109$ data points.

Random Forest models were computed with importance computation set to true and specifying 2000 trees (models converged after 238 trees for predicting LAI and 36 trees for FCover). Predictor variables include: mean of shortwave- infrared (SWIRM) and near-infrared (NIRM) reflectances, dissimilarity of near-infrared (NIRD) and of shortwave- infrared reflectances (SWIRD), and the mean and sd of NDVI within a focal moving window of 8 pixels (NDVIMFocal and NDVISD). Predictor variables and their importance (with standard error in brackets) to the model predictions were ranked using the mean decrease in accuracy (\%IncMSE) estimated based on random permutations using out-of-bag-Cross-Validation. 


\begin{tabular}{|l|l|l|l|l|}
\hline \multirow{2}{*}{ model predictors } & \multicolumn{2}{l|}{$\boldsymbol{L A I}$} & \multicolumn{2}{l|}{ FCover } \\
\hline Variance explained random forest & \multicolumn{2}{l|}{ SWIRM+NIRM+NIRD+ } & \multicolumn{2}{l|}{ SWIRM+NDVIMFocal+NDVISD } \\
\hline \multirow{5}{*}{ Importance } & $\mathbf{3 5 . 3 \%}$ & $0.3064(0.008)$ & NDVIMFocal & $106.531(2.083)$ \\
& NIRD & $0.2816(0.011)$ & NDVISD & $63.572(1.744)$ \\
\cline { 2 - 5 } & NDVIMFocal & $0.2290(0.009)$ & SWIRM & $43.209(1.648)$ \\
\cline { 2 - 5 } & NIRM & $0.1370(0.008)$ & & \\
\cline { 2 - 5 } & SWIRD & $0.1335(0.007)$ & & \\
\cline { 2 - 5 } & SWIRM & & \\
\hline
\end{tabular}

3 